\section{Pacific Northwest}

National Laboratory

Operated by Battelle for the

U.S. Department of Energy

\title{
Turbine Imaging Technology Assessment
}

R.A. Moursund

T.J. Carlson

December 2004

Prepared for the U.S. Department of Energy under Contract DE-AC05-76RL01830 
Pacific Northwest National Laboratory

Operated by Battelle for the U.S. Department of Energy
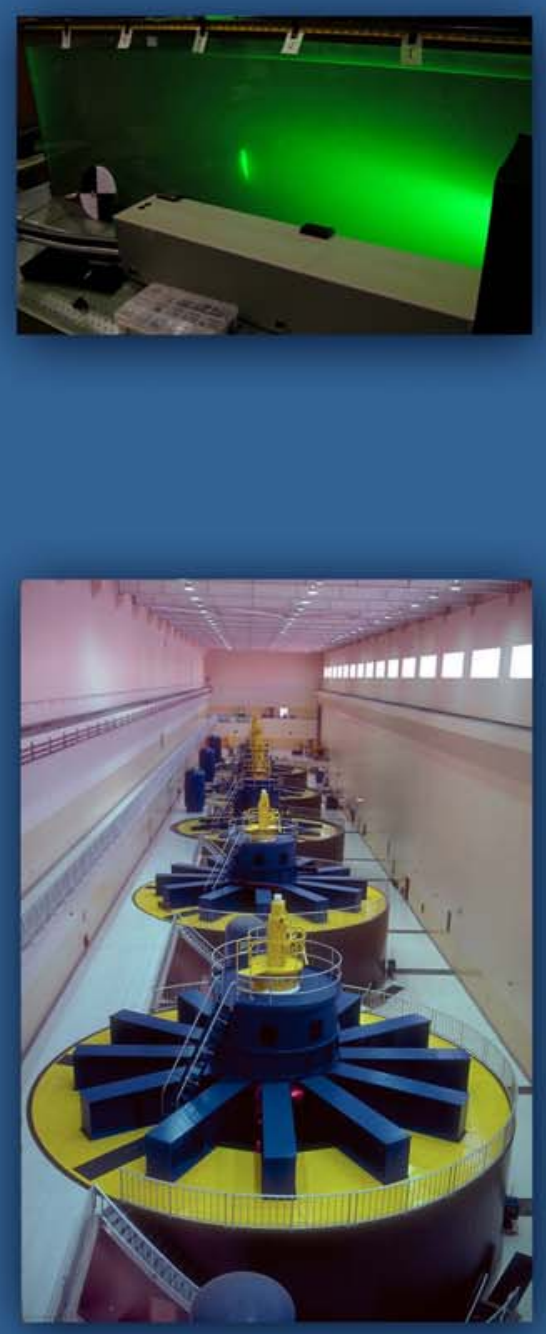

R.A. Moursund

T.J. Carlson

\author{
December 2004
}

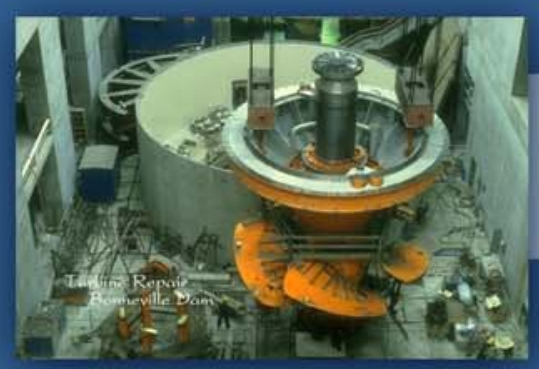

\section{Turbine Imaging Technology Assessment}

U.S. Departinent of Energy

Ejergy Efficjency and Renewable Energy

Wind and Hydropower Technologies 


\section{DISCLAIMER}

This report was prepared as an account of work sponsored by an agency of the United States Government. Neither the United States Government nor any agency thereof, nor Battelle Memorial Institute, nor any of their employees, makes any warranty, express or implied, or assumes any legal liability or responsibility for the accuracy, completeness, or usefulness of any information, apparatus, product, or process disclosed, or represents that its use would not infringe privately owned rights. Reference herein to any specific commercial product, process, or service by trade name, trademark, manufacturer, or otherwise does not necessarily constitute or imply its endorsement, recommendation, or favoring by the United States Government or any agency thereof, or Battelle Memorial Institute. The views and opinions of authors expressed herein do not necessarily state or reflect those of the United States Government or any agency thereof.

\section{PACIFIC NORTHWEST NATIONAL LABORATORY \\ operated by \\ BATTELLE \\ for the}

UNITED STATES DEPARTMENT OF ENERGY

under Contract DE-AC05-76RL01830

Printed in the United States of America

Available to DOE and DOE contractors from the

Office of Scientific and Technical Information,

P.O. Box 62, Oak Ridge, TN 37831-0062;

ph: (865) 576-8401

fax: (865) 576-5728

email: reports@adonis.osti.gov

Available to the public from the National Technical Information Service,

U.S. Department of Commerce, 5285 Port Royal Rd., Springfield, VA 22161

ph: (800) 553-6847

fax: (703) 605-6900

email: orders@ntis.fedworld.gov

online ordering: http://www.ntis.gov/ordering.htm

This document was printed on recycled paper. 


\section{Executive Summary}

Juvenile fish passing through the turbines of hydro electric dams are exposed to numerous injurycausing mechanisms including both fluid and mechanical forces. Previous research has shown that these mechanisms cause similar-looking injuries to fish so most biological testing techniques have been inadequate for identifying specific causes of injury under different operating scenarios. Use of imaging technologies inside the turbines to observe the approach and interaction of fish with turbine structural elements has been proposed as one means for gaining a clearer understanding of causes of injury. In 2003 and 2004 Pacific Northwest National Laboratory conducted an investigation of imaging technologies that included theoretical and laboratory studies.

The goal of this project was to identify and evaluate imaging technologies for observing juvenile fish within a Kaplan turbine, and specifically that would enable us to determine mechanisms of fish injury within an operating turbine unit. This evaluation documents the opportunities and constraints for observing juvenile fish at specific locations during turbine passage. These observations would be used to make modifications to dam structures and operations to improve conditions for fish passage while maintaining or improving hydropower production.

The physical and hydraulic environment that fish experience as they pass through the turbines, including the physical structures of the intake, stay vanes, wicket gates, and runner, were studied and the regions with the greatest potential for injury were defined. Biological response data were also studied to determine the probable types of injuries sustained in the turbine intake and what types of injuries are detectable with imaging technologies. We grouped injury-causing mechanisms into two categories: fluid (pressure/cavitation, shear, turbulence) and mechanical (strike/collision, grinding/pinching, scraping). The physical constraints of the environment, together with the likely types of injuries to fish, provided the parameters needed for a rigorous imaging technology evaluation.

Types of technology evaluated included both tracking and imaging systems using acoustic technologies (such as sonar and acoustic tags) and optic technologies (such as pulsed-laser videography, which is high-speed videography using a laser as the flash). Criteria for determining image data quality such as frame rate, target detectability, and resolution were used to quantify the minimum requirements of an imaging sensor. We based our calculations on the most demanding application -- imaging head injuries to a subyearling Chinook salmon smolt passing through the runner tip region. Previous ex-situ and in-situ study results were used, along with the results from a laboratory experiment we conducted, to address tradeoffs in sensor capability in the typically low-visibility riverine environment. We concluded that a high-speed optical-imaging solution, such as pulsed-laser videography, was the only feasible technology to image fish fast enough and at high enough resolution to detect operculum and eye injuries at the runner tip. Only a laser light source would produce enough light in the extremely short exposure required to prevent image blur from the runner or the fish, which were moving at up to $32 \mathrm{~m} / \mathrm{s}$ through the runner tip region. Finally, optical wavelength scattering due to murky river conditions may limit the range of detection and image resolution to short, but usable, ranges depending on the time of year and the particular river. 


\section{Acknowledgments}

Many people have contributed to the success of this project. Constructive and substantive comments on the draft document were provided by Glenn Čada, Oak Ridge National Laboratory. Rod Wittinger of the Hydraulic Design Center (HDC) at the U.S. Army Corps of Engineer's Portland District provided drawings and hard-to-obtain dimensions. Martin Ahmann of the Corp's Walla Walla District provided turbine hydraulic data. Within the Pacific Northwest National Laboratory (PNNL), we much appreciate Dennis Dauble's involvement and oversight as well as the technical and editorial reviews provided by Kenneth Ham and Theresa Gilbride.

We especially wish to thank the U.S. Department of Energy Office of Energy Efficiency and Renewable Energy's (DOE EE/RE) Wind and Hydropower Technologies Program for supporting this work. 



\section{Contents}

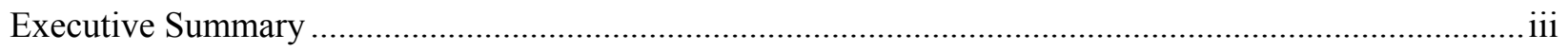

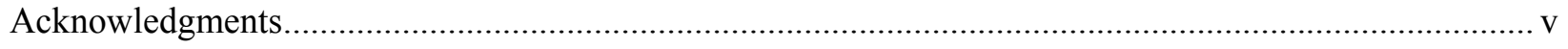

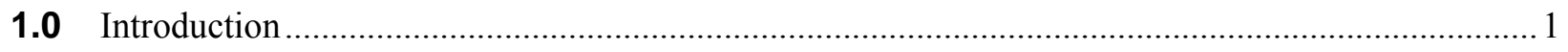

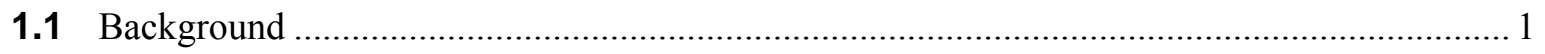

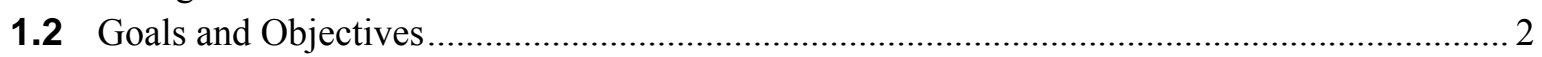

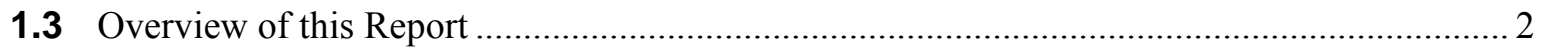

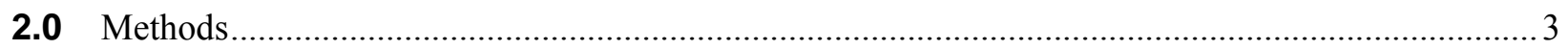

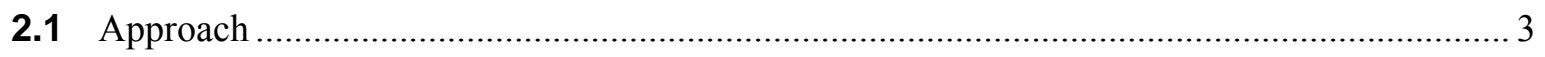

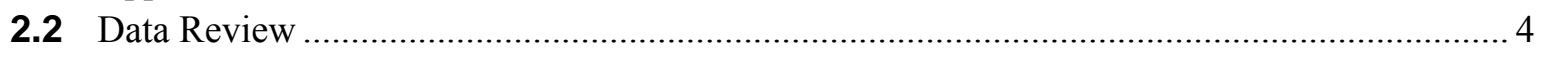

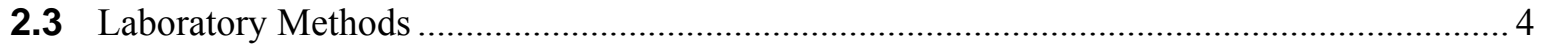

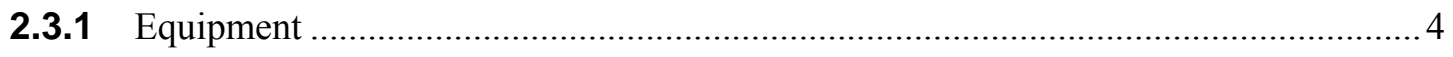

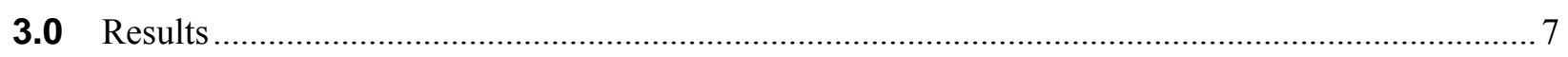

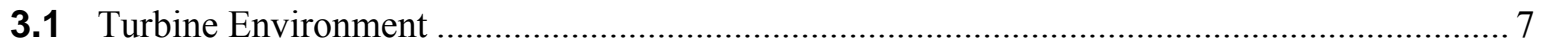

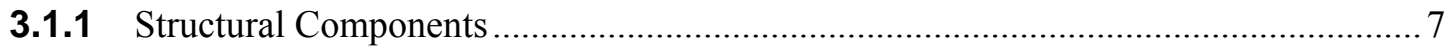

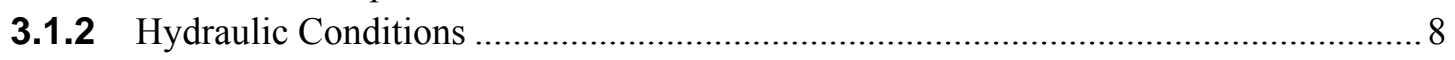

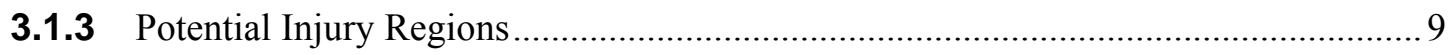

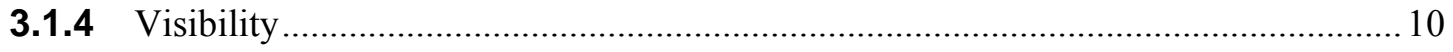

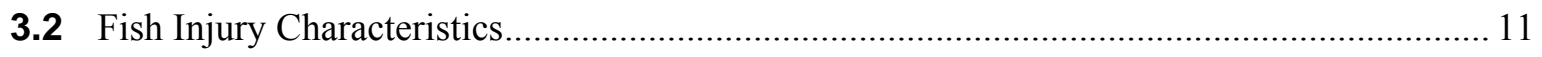

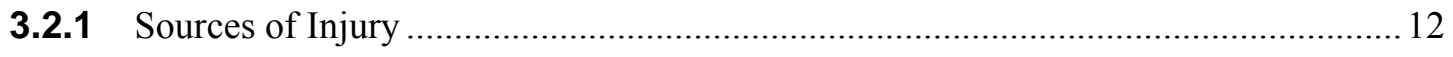

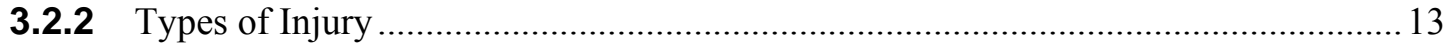

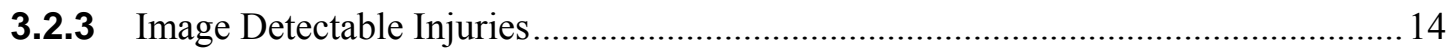

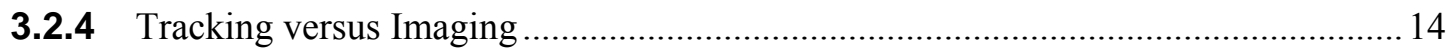

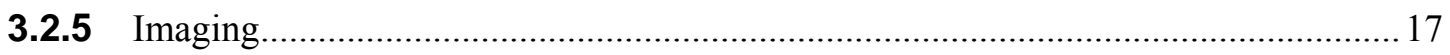

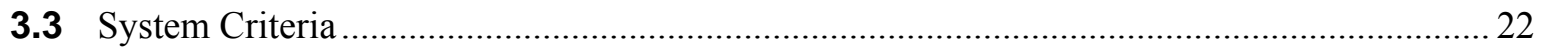

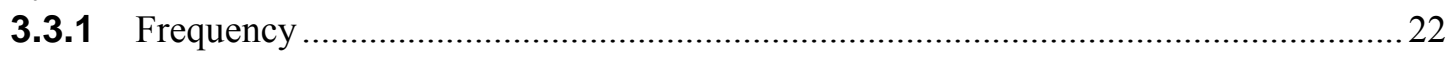

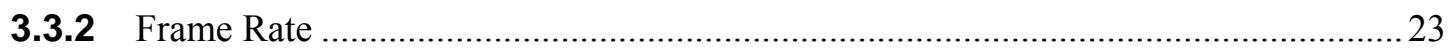

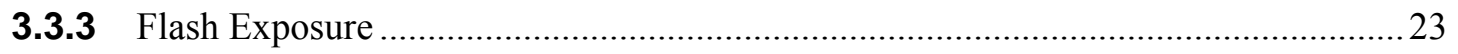

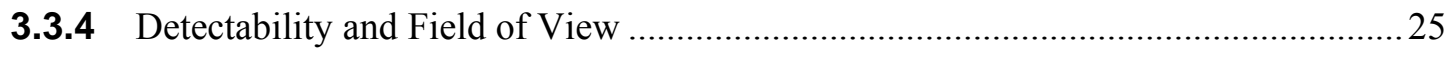

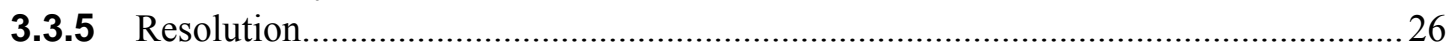

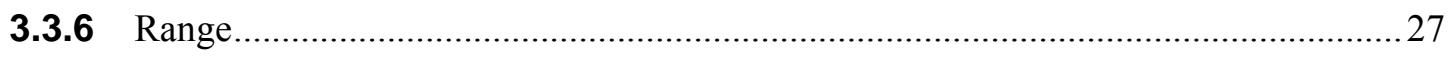

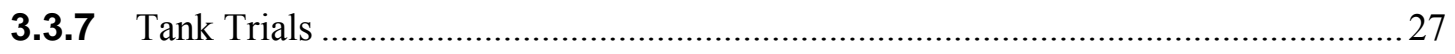

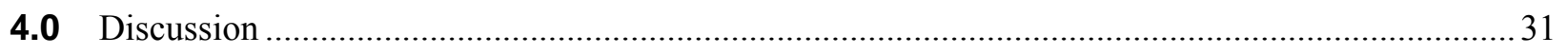

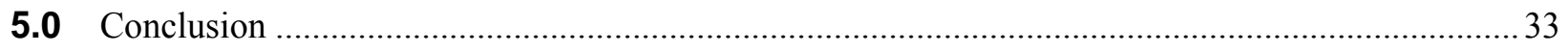

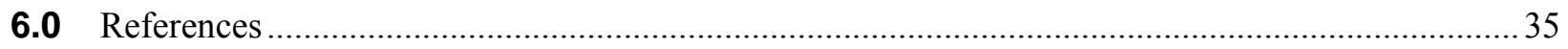




\section{Figures}

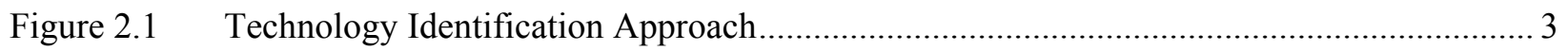

Figure 3.1 Structural Components and Approximate Scale of a Typical Kaplan Turbine Unit ............. 7

Figure 3.2 Relationship between Stay Vanes and Wickets Gates of a Generic Kaplan Turbine........... 8

Figure 3.3 An Ice Harbor Dam Turbine Unit with Generalized Flow Arrows. ................................... 9

Figure 3.4 Order of Encounter and Expected Mean Water Velocities through a Turbine Unit............. 9

Figure 3.5 Turbine Cut Away View. Image courtesy of the U.S. Army Corps of Engineers.............. 10

Figure 3.6 Ice Harbor (Left) and McNary (Right) Seasonal Changes in Visibility over the Fish Passage Season.

Figure 3.7 Box and Whisker Plot of Ice Harbor (IHR) and McNary (MCN) Dam Visibility for the April 15 - July 15 Periods of 1993 through 2002.

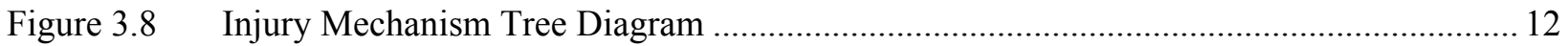

Figure 3.9 Average Size of Subyearling Chinook Salmon Smolt...................................................... 15

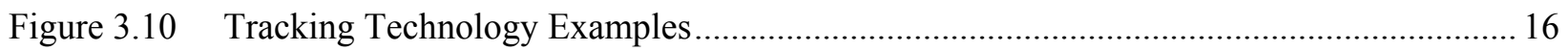

Figure 3.11 Maximum Range of Active Acoustic Tracking or Acoustic Imaging based on the Two-Way Travel Time of Sound Underwater and Hardware Limitations

Figure 3.12 DIDSON Images from The Dalles Dam..................................................................... 19

Figure 3.13 Zoomed Acoustic Images of What are Believed to be Three Yearling Chinook Salmon Smolts at $5.5 \mathrm{~m}$ Range from the Above Image at Left

Figure 3.14 Photos of Laboratory Shear Tank Experiments.......................................................... 22

Figure 3.15 Frame Rate and Exposure Time by Turbine Region .................................................... 25

Figure 3.16 Linear Field of View and Detectability vs. Range by Lens Field of View ......................26

Figure 3.17 Single Pixel Size (mm) vs. Range by Sensor Resolution .............................................. 27

Figure 3.18 Images of a Subyearling Chinook Salmon at Ranges from 0.3 to $1.5 \mathrm{~m}$ from the Laser Light Source on the Right-Hand Side of the Tank with a Visibility of only 0.75 and 1.25 Secchi $\mathrm{m}$ 28 
Figure 3.19 Approximately 1 (left), 0.5 (middle), and 0.25 (right) Megapixel Images of the Subyearling Smolt at $0.9 \mathrm{~m}$ Range and 0.75 Secchi $\mathrm{m}$ of Visibility .

Figure 4.1 Turbine Tracking and Imaging Technologies with the Tradeoffs of Range, Resolution, and Data Type Shown.....

\section{Tables}

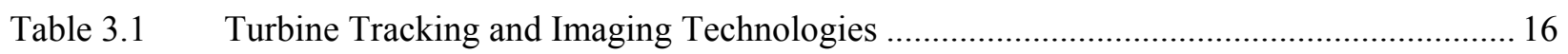

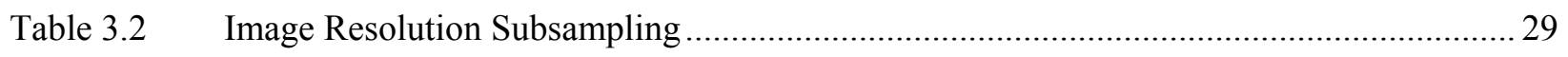

Table 4.1 Relative Performance Features of Acoustic versus Optical Imaging ............................... 32 



\subsection{Introduction}

Juvenile fish passing through the turbines of hydro electric dams are exposed to numerous injurycausing mechanisms including fluid (pressure/cavitation, shear, turbulence) and mechanical (strike/collision, grinding/pinching, scraping). Previous research has shown that fluid and mechanical injury mechanisms can cause the same or similar-looking injuries to fish. Therefore, balloon tag, fyke net, and other biological testing of fish is inadequate for gaining a complete understanding of the primary causes of injury under different operating scenarios. Use of imaging technologies in the turbines has been proposed as one means for gaining a clearer understanding of causes of injury. In 2003 and 2004 Pacific Northwest National Laboratory conducted an investigation of imaging technologies that included theoretical and laboratory studies.

\subsection{Background}

Essentially all prototype-scale studies of the impact of turbine passage on fish treat the turbine as a "black box;" that is, fish are injected or allowed to pass into the turbine intake and are recovered or detected upon exit without direct knowledge of the conditions that they experience. Balloon tag studies provide one opportunity to recover and examine fish immediately following turbine passage (Carlson 2001). Other active and passive tagging methods, through a variety of experimental designs, have permitted estimation of turbine passage survival and, in some recent studies, separation of total turbine mortality into direct and indirect mortality components. Direct mortality is that portion of total turbine passage route mortality that occurs within the turbine unit, but mechanisms of injury can only be inferred from the types of injuries observed. Indirect mortality takes place in the powerhouse tailrace and is thought to be primarily due to predation on turbine-passed fish. Indirect mortality is believed to be linked in some manner to injuries sustained during turbine passage that make the fish more vulnerable to predation. A general result from these studies is that indirect mortality typically accounts for one-half to two-thirds of total turbine mortality (USACE 2004).

In an effort to understand the mechanisms for injury to fish during turbine passage and the locations at which injury occurs, 1:25 scale physical turbine models have been constructed and used to observe the passage of particles through the model turbine environment and to obtain observations of turbine fluid dynamics (Carlson 2001). The rates of exposure to conditions capable of causing injury in these models are several times those resulting in physical injury during balloon tag studies. It is unclear how to interpret these findings from particle tracking in physical models because there are no comparable data sets at prototype scales that can be used to calibrate and validate physical model estimates for events such as strike.

Laboratory studies clearly show that some fish exposed to conditions capable of causing injury are not injured (Neitzel et al. 2003). Injury and mortality rates are almost always correlated with the severity of exposure. Sensor Fish, an autonomous pressure and accelerometer sensor package developed by PNNL for DOE, can provide actual data on pressures and accelerations experienced during passage through a dam; however, it is difficult at this time to correlate this data with physical injuries. The primary challenge with laboratory studies remains how to apply the results in a quantitative way to actual turbine passage conditions. 
Current state-of-the-art study of fish passage through turbines includes a rather large number of "black box" studies of fish passage through operating turbines, a relatively small number of focused laboratory studies, and an equally small number of invalidated, physical-model particle-tracking studies (Carlson 2001; USACE 2004). The integration of results from these three types of studies has been minimal. Detailed observations at the prototype scale are needed to assess the applicability of the various laboratory and physical model studies and to provide the information necessary to permit their use where applicable. To understand and quantify fish injury mechanisms, there is a need to observe fish interacting with structural elements and hydraulic conditions in turbines.

\subsection{Goals and Objectives}

The goal of this project was to identify and evaluate alternatives for observing behavioral details of juvenile fish within an operating Kaplan turbine unit, focusing on methods to determine fish injury mechanisms. Methods are particularly needed to observe the approach and interaction of fish with turbine structural elements. The immediate objective is to identify and perform a desktop/ laboratory evaluation of technologies that might be used to observe juvenile fish at specific locations during turbine passage.

This report is one of two and covers turbine imaging technology assessment. The subsequent report will be a turbine-imaging deployment prospectus and will contain a thorough discussion of implementation details and equipment specifications.

\subsection{Overview of this Report}

Chapter 2 describes methods used in our evaluation of imaging technologies. Chapter 3 describes results of our findings. Chapter 4 is a discussion of the findings. Chapter 5 is conclusions. Chapter 6 is references. 


\subsection{Methods}

This investigation sought to identify technologies for the quantification of causal mechanism(s) of injury to smolts during turbine passage. First, we considered the turbine environment in terms of physical scale and environmental characteristics. Second, juvenile migratory fish are described in terms of scale and susceptibility to injury. Together these factors define the challenge of imaging the interaction of fastmoving fish and machinery. Given these challenges, technical requirements were specified for sensors that will perform within the turbine environment.

\subsection{Approach}

The requirements imposed by the physical environment were first quantified. That environment includes the physical structures of the intake, stay vanes, wicket gates, and runner. It also includes the hydraulic environment that fish will experience as they pass through the turbine. Imaging equipment must not only survive this environment, it must also capture images of sufficient quality to identify the causal mechanisms of injury.

The requirements imposed by the biological subject were studied by defining what types of injuries occur in the intake and what types of injuries can be detected with imaging techniques. Results from other turbine passage studies offered substantial insight into both possible and likely injury types. Detailed accounts from both ex-situ and in-situ study results were integrated to narrow the focus of likely injuries that would be detectable by imaging.

Once the requirements were determined, potential technologies were reviewed given the expected conditions inside the turbine intake. Images from a variety of sources were examined, and detailed system selection constraints were generated. These included image quality measures, frame rate, space, cable, and power requirements. Finally, laboratory tests were used to predict instrument performance in the field. Figure 2.1 is a diagram of the process used and the explicit need to incorporate these sources to predict imaging system performance.

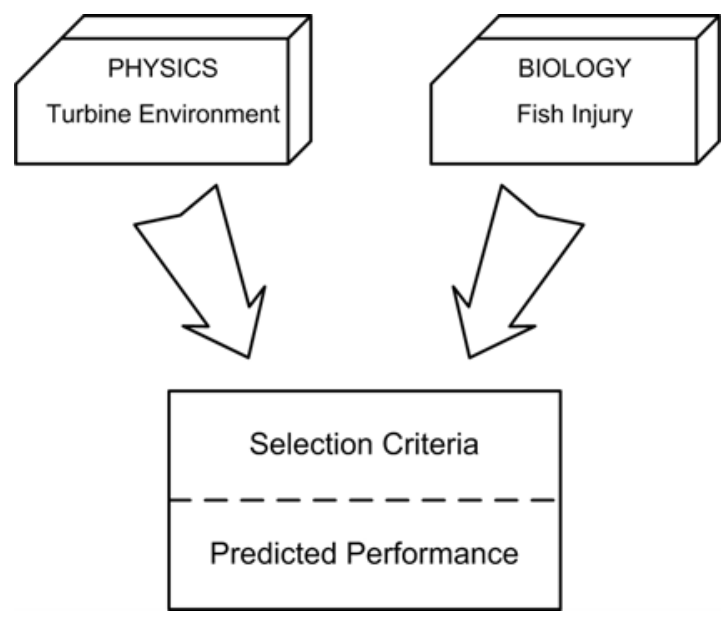

Figure 2.1. Technology Identification Approach 


\subsection{Data Review}

Much of the background for this study has come from proceedings and projects of the U.S. Army Corps of Engineers (USACE) Turbine Survival Program and the U.S. Department of Energy (DOE) Advanced Hydropower Turbine Systems program (Carlson 2001; Wittinger et al. 1995; USACE 2004). Additional sources included literature on the physics and application of various sensors (Frouin and Gilbert 2002; Mobley 1994; Seyrafi and Hovanessian 1993; Sidney 2002; Uric, 1983). The Columbia River Data Access Real Time website (http://www.cqs.washington.edu/dart/dart.html) provided river environment data.

Engineering drawings obtained from the USACE provided the spatial relationship of the structures and mechanical components of a turbine unit. Data from USACE physical flow models provided the estimates of water velocities at various discrete locations up to the flow vanes. Studies conducted at the dams with balloon tagged fish provided in-situ data on fish injuries directly attributable to turbine passage. Few other options exist at the present for the in-situ biological testing of fish through a turbine unit. Ex-situ experiments have been conducted in the laboratory exposing fish to conditions designed to simulate passage through a turbine unit. Special facilities have been built to isolate passage variables, such as pressure or shear. Both the in-situ and ex-situ biological studies have been valuable for showing what types of injuries can be expected from turbine passage.

\subsection{Laboratory Methods}

A small laboratory-scale experiment was conducted to address uncertainties associated with predicting the performance of an imaging system, in particular, the effects of turbidity on resolution as no theoretical prediction of this effect was available. Basic optical system components were tested by PNNL in a laboratory reproduction of typical low-visibility spring-freshet river water conditions.

\subsubsection{Equipment}

The test equipment used was primarily instrumentation designed for particle image velocimetry. A laser was used to provide a very powerful light source. The laser frequency was also optimized for transmission through water and of a type that could be strobed very quickly for the velocimetry application. Because of recorded turbidity levels at a typical mainstem dam, an optical imaging system was not expected to be useful at very long ranges; thus a $1.5-\mathrm{m}$ long tank was able to provide sufficient range for testing.

An industrial laser table held all of the components. The laser was a diode-pumped Nd:YAG model LDP-100MQG from Lee Lasers with the frequency doubled to give a 532-nm wavelength. This laser is capable of up to 50-W output, operates on a $220 \mathrm{VAC} / 15 \mathrm{~A}$ circuit, and has a water-cooled flash tube. The laser was set to continuous (non-pulsed) output of $5 \mathrm{~W}$ for the tank trials. To fit within the space available in the tank, the light path was angled through two mirrors for the beam to make a U-turn and enter the end of a $0.46 \times 0.61 \times 1.52 \mathrm{~m}, 567 \mathrm{~L}$ glass tank. Since each of the mirrors results in a $15 \%$ loss, the amount of power entering the side of the tank was about $2.8 \mathrm{~W}$. Just prior to the light reaching the tank, it passed through a prism to form a $1-\mathrm{mm}$ by $20^{\circ}$ light sheet. 
The tank was filled with raw Columbia River water. The first series of measurements was taken under 1.25 Secchi $\mathrm{m}$ of visibility. Then a turbidity enhancing agent was added to reduce visibility to 0.75 Secchi $\mathrm{m}$. These values are typical of the poorest visibility of the spring freshet in the Columbia River. This represents a worst-case scenario for an optical imaging system, as visibility tends to gradually increase over the summer. A euthanized $92-\mathrm{mm}$ hatchery subyearling Chinook salmon smolt was suspended at $0.3-\mathrm{m}$ intervals at mid-depth across the tank. Photographs were taken with a 5.0 mega-pixel (Nikon 5700) digital camera. The images were examined to determine the level of detail available for the purpose of identifying injuries. 



\subsection{Results}

\subsection{Turbine Environment}

This section describes the physical components of the turbine environment with the objective of identifying the constraints to deployment and operation of imaging devices. In order of opportunity they are the area immediately upstream of the turbine stay vanes and wicket gates and the area immediately upstream of the turbine runner. Considerations include scale, hydraulic conditions, injury regions, and visibility.

\subsubsection{Structural Components}

The Kaplan turbine units in service on the lower mainstem Columbia and Snake Rivers have 5- or 6blade runners that operate in the 70 to 90 revolutions-per minute range. Water and fish first enter the intake; then the scroll case; then pass the stay vanes, the wicket gates, and runner; and finally exit via the draft tube (Figure 3.1). The McNary Dam intake, as an example, is $11.2 \mathrm{~m}$ wide as it enters the scroll case. The stay vanes are fixed structural elements approximately $0.3 \times 0.1 \times 2.9 \mathrm{~m}$. Immediately beyond these are the wicket gates, which act as the flow control mechanism and are slightly larger elements measuring $0.7 \times 0.1 \times 2.9 \mathrm{~m}$. Water then enters the runner region, bounded by the hub and discharge ring. The McNary runner is $7.1 \mathrm{~m}$ in diameter at the discharge ring. Once past the runner, water flows into the draft tube before being discharged into the tailrace.

The wicket gates are controlled by an articulated stay ring in the turbine pit that manipulates all the gates in unison. The wicket gates are continuously adjustable from fully open to fully closed positions to regulate the flow of water into the unit (Figure 3.2). Depending on the position of the wicket gates, the trailing edge of the stay vane may not line up with the leading edge of the wicket gate. Thus the leading edges of both the stay vane and the wicket gate are potential sources of injury depending on flows.

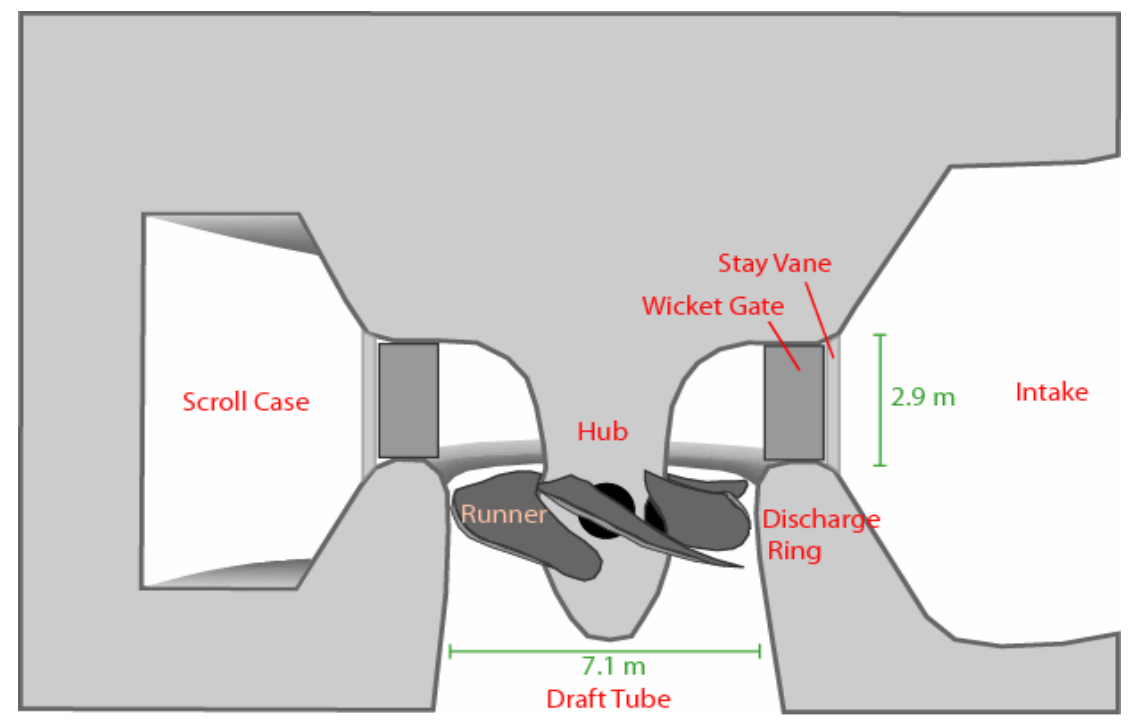

Figure 3.1. Structural Components and Approximate Scale of a Typical Kaplan Turbine Unit 

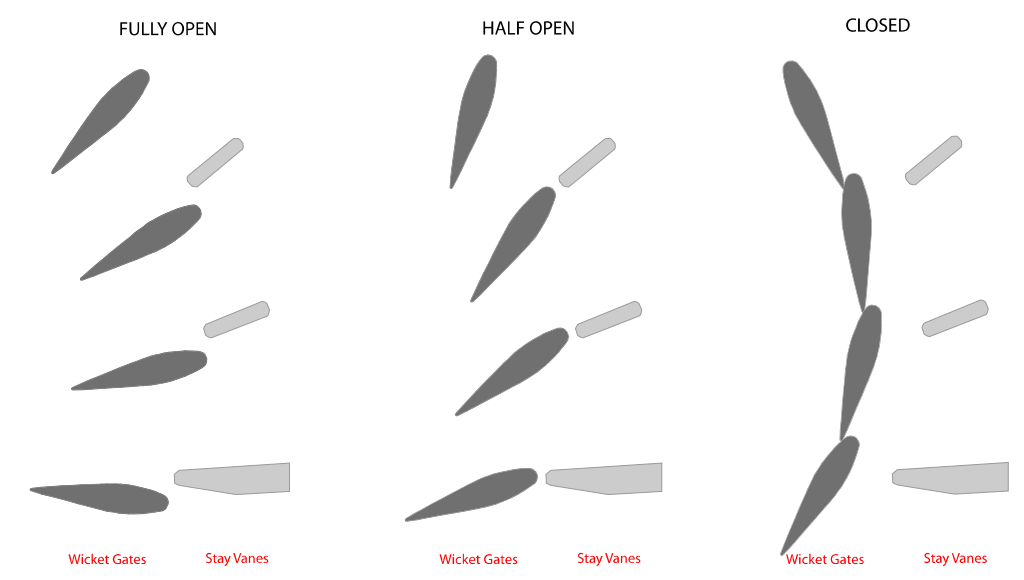

Figure 3.2. Relationship between Stay Vanes and Wickets Gates of a Generic Kaplan Turbine

\subsubsection{Hydraulic Conditions}

Water enters the scroll case via three intakes. Flows through each of these intakes are asymmetric with one slot (shown with the split arrow) drawing a higher volume of water than the others (Figure 3.3). The presence and type of intake fish screen, e.g., submersible traveling screens (STS) and extendedlength bar screens (ESBS), also influence the flows through the intake. Both types of screens can dramatically alter the vertical distribution of flow, and their hydraulic influence extends through the entire turbine unit.

Water velocities gradually increase in the intake and continue to accelerate up to and through the runner region. The magnitudes of these velocities are an important physical characteristic for both fish and any monitoring equipment. Flow actually experienced by fish inside the flowfield will be considerably less from a relative standpoint; however, the flow conditions relative to structures will be relevant for imaging equipment requirements. Based on physical models, mean flows are estimated to enter the intake at 0.6 to $0.9 \mathrm{~m} / \mathrm{s}$ and are 1.8 to $2.7 \mathrm{~m} / \mathrm{s}$ by the time they exit the intake. From physical model data, flows approaching the stay vanes range from 3 to $7 \mathrm{~m} / \mathrm{s}$. Flow in the areas between the wicket gates and the runner is 15 to $18 \mathrm{~m} / \mathrm{s}$ with the highest flows in this region experienced near the bottom of the stay ring and in the presence of an ESBS. Velocities of the rotating runner fior a typical Columbia River turbine, calculated from the simple geometry of the runner diameter and revolution speed, range from $8 \mathrm{~m} / \mathrm{s}$ near the hub to $32 \mathrm{~m} / \mathrm{s}$ at the tip of the runner. Maximum mean velocity at the draft tube when water exits the runner is $6 \mathrm{~m} / \mathrm{s}$ with the same velocities maintained past any flow divider wall(s). Mean water velocity at the draft tube exit in the tailrace is $5 \mathrm{~m} / \mathrm{s}$. These velocities are shown graphically below with emphasis on the range of runner velocities (Figure 3.4). The residence time in each region, and the transitions between each one, are not well understood for fish and are intentionally not shown. 

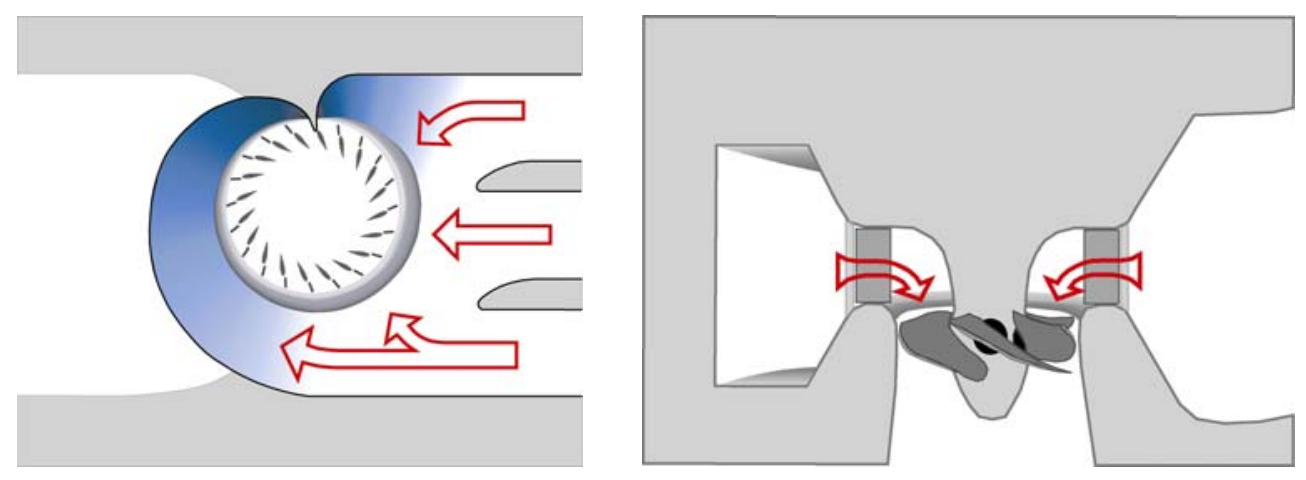

Figure 3.3. An Ice Harbor Dam Turbine Unit with Generalized Flow Arrows. Top view (left) and side view (right).

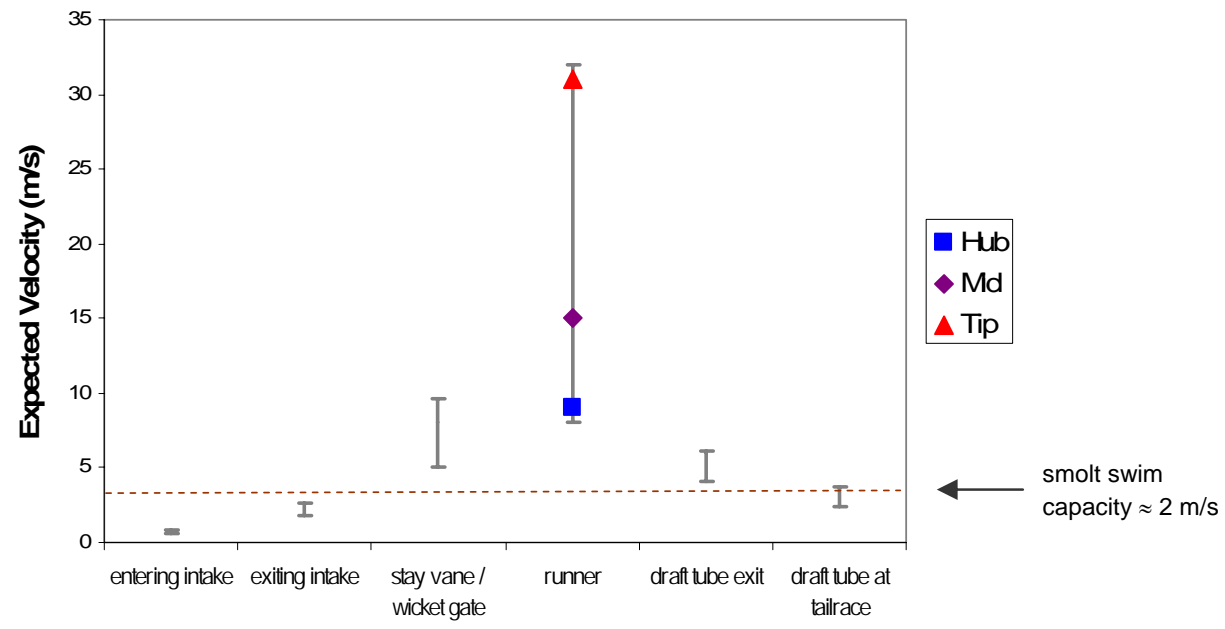

Figure 3.4. Order of Encounter and Expected Mean Water Velocities through a Turbine Unit. The actual residence time in each region is not shown. Hub, mid, and tip are point locations along the runner.

\subsubsection{Potential Injury Regions}

To facilitate discussion of fish injury during turbine passage, specific regions in the scroll case where fish injury is most likely to occur are defined as shown in Figure 3.5. The first region is the stay vanes. Fish may potentially impact the leading edge of the vanes, or scrape along their surface (Figure 3.5). This region is an area of concern because of the relatively large number of neutrally buoyant particles that impacted the stay vanes in 1:25 scale turbine model testing (Carlson 2001). The next region is the wicket gates. Since the trailing edge of the stay vane and the leading edge of the wicket gate aren't always lined up, the wicket gates represent another region for potential fish impact and/or scraping. In addition to strike potential, these surfaces could spin off small high-energy (damaging) vortices. 
The last three regions of interest for imaging are areas along the runner. These regions are representative of a spectrum of hydraulic phenomena that fish may encounter along the runner as evidenced by the range of velocities occurring along the runner, which are listed in Figure 3.5. These numbers do not indicate the relative water velocities within those regions, and therefore are not what fish necessarily experience. However, if we assume a no-slip boundary condition at the runner surface, then at least some water is moving at this maximal velocity. In addition, gaps may exist near the hub and discharge ring, representing a mechanical type of passage hazard.

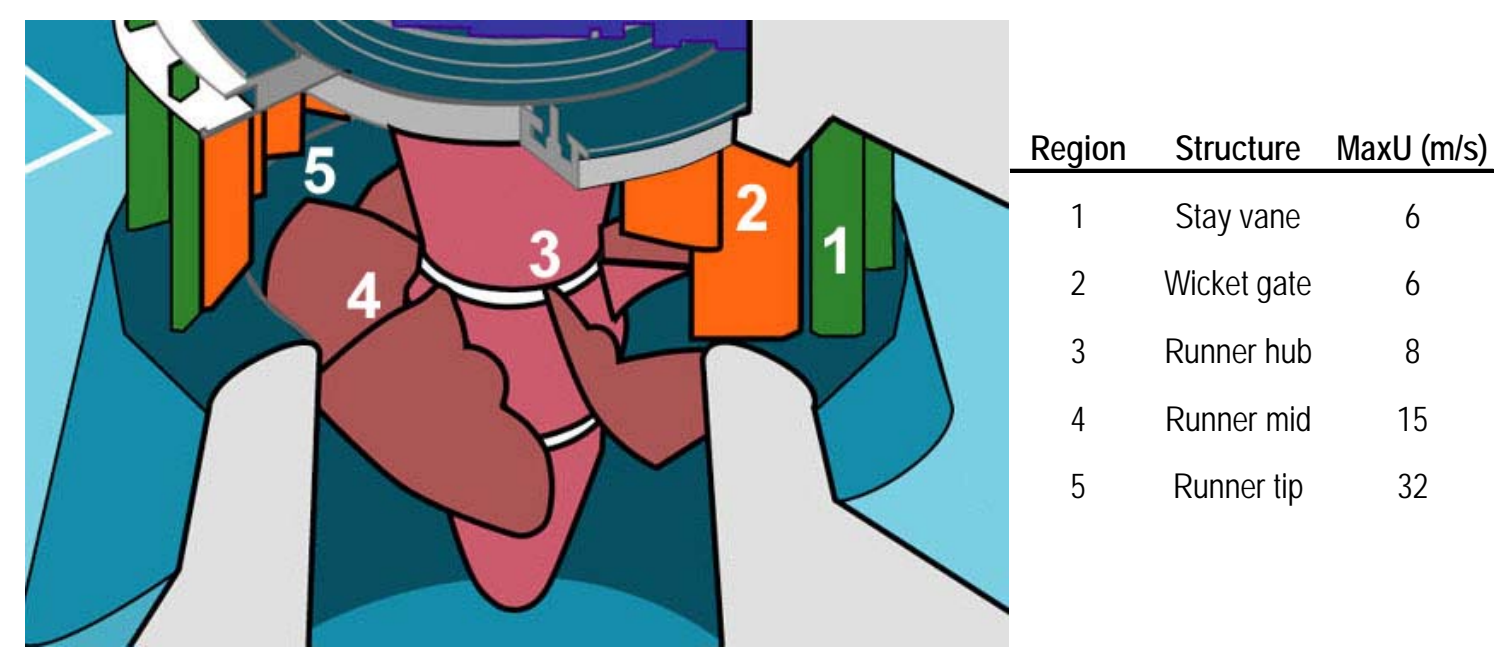

Figure 3.5. Turbine Cut Away View. Image courtesy of the U.S. Army Corps of Engineers.

Other regions for potential injury exist outside this focus area and could include screening and/or gatewell components in the intake region or the draft tube with its splitter pier noses. These are relatively lower velocity areas. The potential indirect effects of passage through the unit, e.g., the immediate tailrace region, are beyond the scope of this investigation.

\subsubsection{Visibility}

Fish use light for orientation, and artificial lighting is commonly used in juvenile bypass systems to guide fish, e.g., into a lit gatewell orifice. The only source of light in the turbine environment, however, is ambient light from the intake. Ambient light levels are far too weak for our use in visual detection of smolts, but this naturally dark background may be used to advantage in some cases. For example, a light source could be attached to fish in the form of a light-emitting tag which would show up with greater contrast in the dark turbine environment as demonstrated by Carlson and Weiland (2001). Artificial lighting can be used for the optical detection of fish, in which case visibility is an extremely important environmental variable. An infrared light source has the advantage of being outside the optical sensitivity of fish (and humans). It has greater attenuation, but has been used successfully in operating intakes on intake bar screens for the in-situ observation of juvenile lamprey (Moursund et al. 2003b). Visibility is not generally a factor for acoustic methods over the 10-m ranges found in the intake and scroll case regions, as the particulate organic matter in the water will not obscure acoustic images at the approximately $1 \mathrm{MHz}$ or less frequencies of operation typically used (Moursund et al. 2003a).

Mean visibility at Ice Harbor and McNary Dams is 0.9 Secchi m (15-Apr to 15-July period from 1993 to 2002). Visibility was poorest during the early spring and gradually improved into the summer (Figure 
3.4). Ice Harbor generally has slightly better visibility (10-yr median is 1.1 Secchi m) than McNary (10yr median is 1.0 Secchi $\mathrm{ft}$ ) and increases more rapidly (Figure 3.7). Based on these data, spring conditions at one of these dams or a similar location are expected to have 0.9 Secchi $\mathrm{m}$ or better visibility.
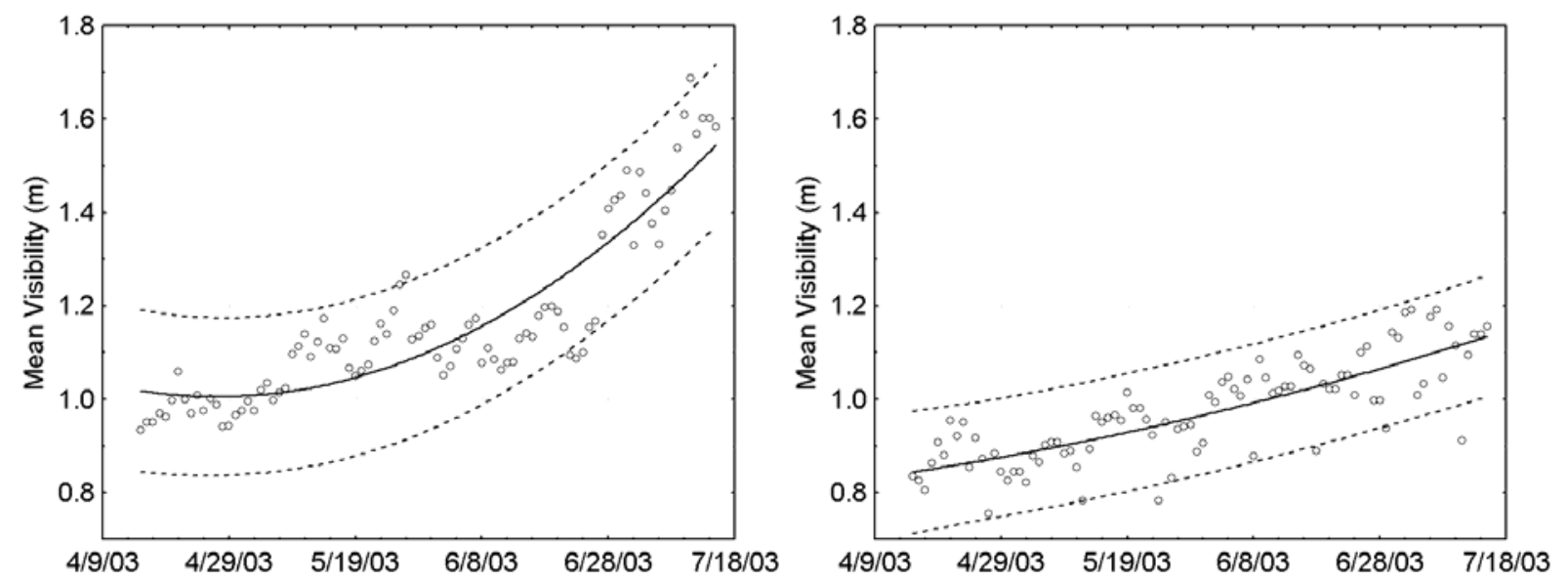

Figure 3.6. Ice Harbor (Left) and McNary (Right) Seasonal Changes in Visibility over the Fish Passage Season. Solid curve shown is a second-order polynomial fit with dotted lines representing the $95 \%$ prediction interval.

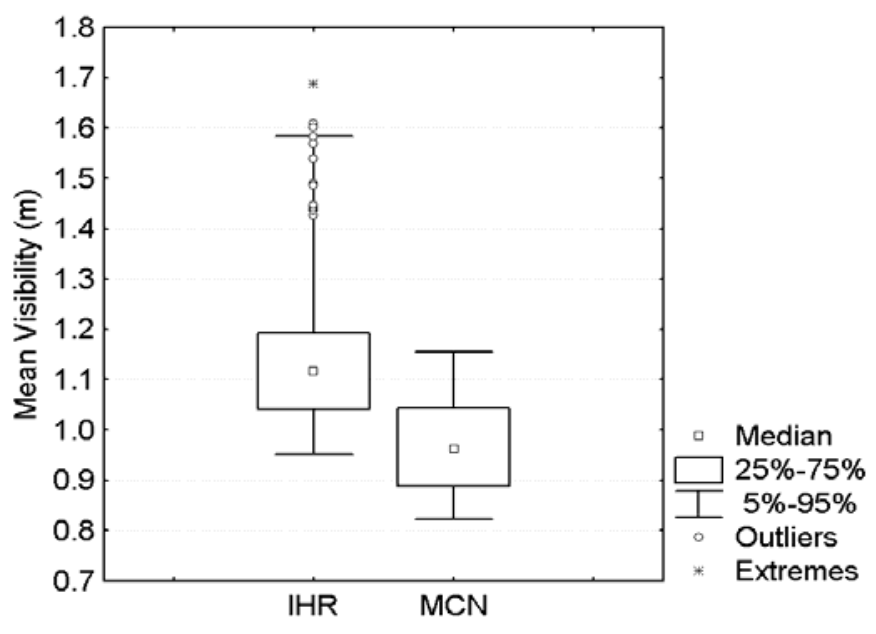

Figure 3.7. Box and Whisker Plot of Ice Harbor (IHR) and McNary (MCN) Dam Visibility for the April 15 - July 15 Periods of 1993 through 2002.

These values are important as they set the worst case scenario for visibility in the region at early spring, the same time that most species of juvenile salmonids begin their downstream migration.

\subsection{Fish Injury Characteristics}

This section describes the characteristics of data sets derived from images that could be used to quantitatively describe the approach and interaction of juvenile fish with turbine structural elements. The primary source of data, regardless of the technology used, would be image time series of interaction events. These time series would be able to show the mechanistic cause of injury within parts of the 
turbine unit that are not well understood. Once the causal mechanisms are understood, they can be incorporated into modeling and testing as the basis for designing turbine units that are more fish friendly.

\subsubsection{Sources of Injury}

Potential sources of injury include pressure, cavitation, strike, grinding, shear, and turbulence from a theoretical perspective (Čada et al. 1997; Wittinger 1995). In addition, fish survival studies from balloon tag releases have referred to pinching as a source of injury (Carlson 2001). In general, these sources may be divided into two groups based on their physical origin: fluid and mechanical (Figure 3.8). Since nomenclature is not consistent within the existing body of literature, the conceptual diagram in Figure 3.8 merges similar concepts relating to the originating phenomena that cause injuries.

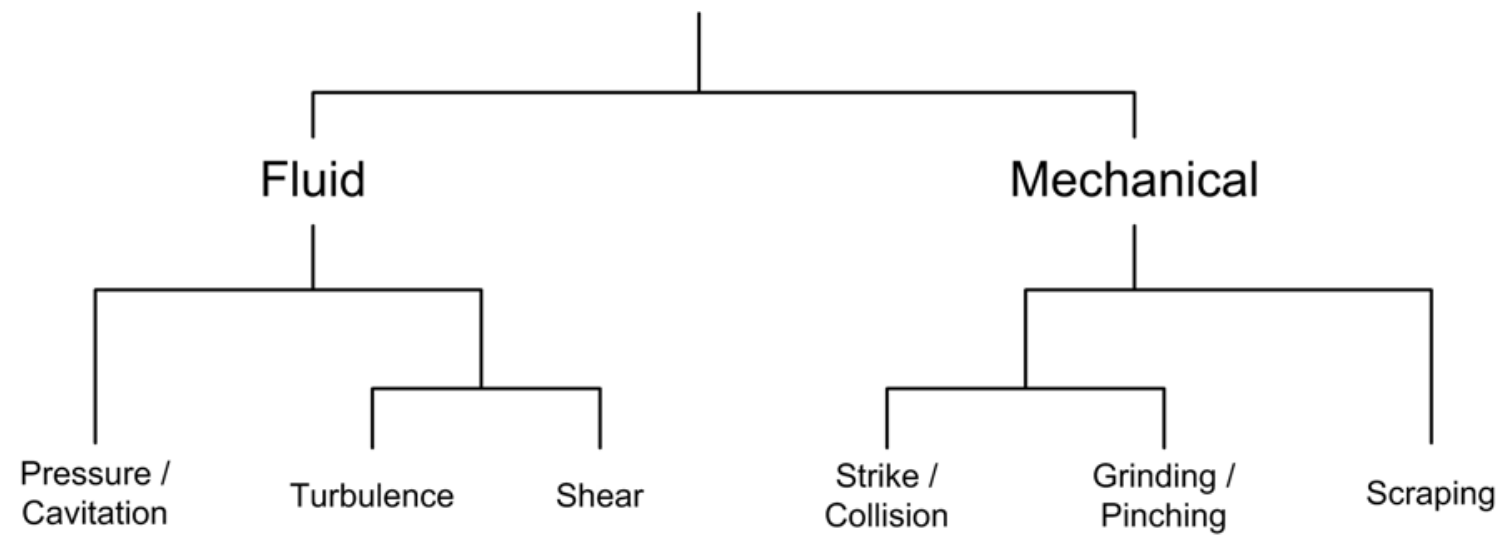

Figure 3.8. Injury Mechanism Tree Diagram

Under fluidic mechanisms of injury, the greatest damage from pressure and cavitation are thought to be associated with the brief $(200 \mathrm{~ms}, 0 \mathrm{~atm})$ negative pressure spike just downstream of the blades. Early works separated pressure from cavitation as potential sources where pressure-related injuries could be caused by either increasing or decreasing the pressure exposure due to the path taken through the intake, runner, and draft tube. Over-inflation of the swim bladder and embolism were concerns from a theoretical standpoint and have been observed in laboratory tests (Abernethy et al. 2002 and 2001). Cavitation, on the other hand, is the rapid formation and collapse of vapor cavities in a fluid. In this conceptual framework, cavitation can be considered a special case of the pressure scenario. Cavitation can produce shock waves upon collapse of the vapor bubble. The possibility of this happening within the body tissue was the main concern, but this does not now appear to be the mechanism for injury due to pressure. Implosion and the resulting shock wave very near the fish may still be a mechanism for causing tissue damage.

Shear and turbulence are related hydrodynamic terms. Shear is the difference in flow or velocity over some distance, whereas turbulence is the difference in flow or velocity over time. Shear and turbulence are, along with many other mathematical formulations, descriptors of the flow phenomenon. They may also be thought of as different perspectives, or points of view, of the same reality and both vary with scale. While many other mathematical descriptors of flow exist, these two have received all of the attention in discussions regarding fish injury. Hydrodynamic shear can be a direct cause of injury for fish (Neitzel et al. 2000), while the focus of turbulence-related research has been on indirect mortality in the immediate tailrace (Odeh et al. 2002). 
Strike is the mechanical action of the blade striking a fish. Collision is a more general term for two bodies impacting. A fish may collide with the leading edge of a flow splitter piernose or stay vane, for instance. Grinding and pinching are equivalent terms describing injuries sustained when a fish is caught between the moving runner blade and a stationary structural element, e.g., the stationary discharge ring. Pinching may be accentuated in the presence of gaps that exist between the runner and hub, and between the runner and discharge ring. Minimization of these gaps as a way to minimize fish injury is the design basis for the minimum gap runner turbine design.

Scraping is an abrasion caused by sustained contact with a structural surface which results in the visible descaling or exposure of tissue beneath the skin of the fish. Removal of the protective layers of slime and scales can leave fish more susceptible to infectious disease. The exact amount of scraping or descaling necessary to have a detrimental impact on smolt survival is not well documented, although scraping injuries seen in the turbine environment generally cause superficial injury without deep tissue damage. Based on limited laboratory study, this type of injury is not a source of immediate mortality (Bouck and Smith 1979).

\subsubsection{Types of Injury}

Fish injuries from turbine exposure have been recorded in-situ from balloon tag studies (Carlson 2001) and ex-situ from turbine passage simulation in laboratory studies (Neitzel 2000). Observed injuries associated with turbines range from bruising to decapitation, and in the case of in-situ studies the precise causal mechanisms are not known. It is difficult to infer mechanism from injury, as both fluidic and mechanical phenomena can create of the same types of injuries. It is important to realize that lethal injuries can occur without direct contact with a solid surface. Many types of injuries associated with mechanical causes have been duplicated ex-situ in shear experiments.

Numerous injury types could occur from strike/collision, grinding/pinching, or shear. Relatively benign injuries include lacerations and external hemorrhaging. A more common laceration is the torn operculum. External hemorrhaging can occur from the gills and/or the eye. More serious injuries involve various avulsions of tissue, up to and including decapitation. The eye, for instance, may be dislodged or removed. Partial decapitation refers to an event where the head is pulled off except for the isthmus, and the gills remain intact. Pinched fish, from ex-situ studies, are those that appear to be cleanly severed in half.

Pressure and cavitation can cause direct lethal injury to fish. Since the initiation of specific laboratory-scale studies (Abernethy et al. 2001 and 2002), the types and mechanisms of pressure-related injuries are relatively well understood. Laboratory studies of gas bubble trauma and the effect of total dissolved gas levels on fish have also been conducted (Montgomery Watson 1995). Initial concerns were that the rapid decrease in pressure in the region just downstream of the runners would cause rupturing of the swim bladder, internal bleeding, or embolism (in the heart atrium or afferent lamellar arteries of the gills). Laboratory studies confirmed that the pneumatic duct of physostomous fish gives protection against swim bladder rupture, but physoclistous fish remain vulnerable. Those injuries that do occur will not be visible externally and will not be detected with external imaging.

Turbulence is currently viewed as causing disruption to the vestibular system of fish. This effect would cause a delayed or indirect mortality associated with increased susceptibility of smolts to predation following turbine passage (Čada et al. 2003; Čada et al. 1997; Carlson 2001). This type of delayed 
mortality effect will not be measured by an imaging system. While turbulence is present at various scales throughout the hydraulic environment, shear is expected to be the dominant injury mechanism in the runner region. The draft tube and exit into the tailrace are the regions where turbulence is suspected to be the dominant injury mechanism.

\subsubsection{Image Detectable Injuries}

The primary mechanisms of direct injury amenable to detection by imaging would be scraping, strike/ collision, grinding/pinching, and shear. With both the runner and fish in an image simultaneously, the exact mechanism of injury could be observed, e.g., shear vs. strike. Even with a time series of images, injuries must be immediate, external, and large enough to be visible.

The average yearling Chinook salmon smolt expected at the mainstem dams on the Columbia River in the spring are $150-\mathrm{mm}$ total length. An average subyearling Chinook salmon smolt, during the summer run, is $90-\mathrm{mm}$ total length. The calculations made in the remainder of this section assume that the limiting size of fish is $90 \mathrm{~mm}$. This fish is about $1 \%$ of the runner diameter. The injury area is assumed to be one-twentieth of the fish's total length, since studies have shown that the eye and operculum are sensitive areas. The smallest "major" shear injuries from lab and field studies are ruptured/missing eyes and bent or torn operculum/isthmus. In terms of scale, the eye injuries are relatively common and also a relatively small visible feature. The eyeball is $5 \mathrm{~mm}$. An operculum flare would be on the order of 10 $\mathrm{mm}$ (Figure 3.9). The scale of these features drives the requirement for minimum resolution of injury detection. Injuries to the eye, operculum, and isthmus will be visible if an eye injury is visible, and decapitation or severing will be obvious. These injuries are all visible injuries that can be imaged, if sufficient attention is paid to ensure their detection, and are also the most common types observed in the existing body of literature.

\subsubsection{Tracking versus Imaging}

The goal of this investigation is to identify an imaging technology suitable for determining the causal mechanism of injury in turbine-passed fish. The technology identified needs to be able to provide images of individual fish as they pass through the turbine at high enough resolution that individual components of the external anatomy of the fish can be clearly seen to determine what happens during an injury event. This goal is distinct from tracking technologies; their purpose is to locate a fish's position over time as it passes through various regions of the turbine. 


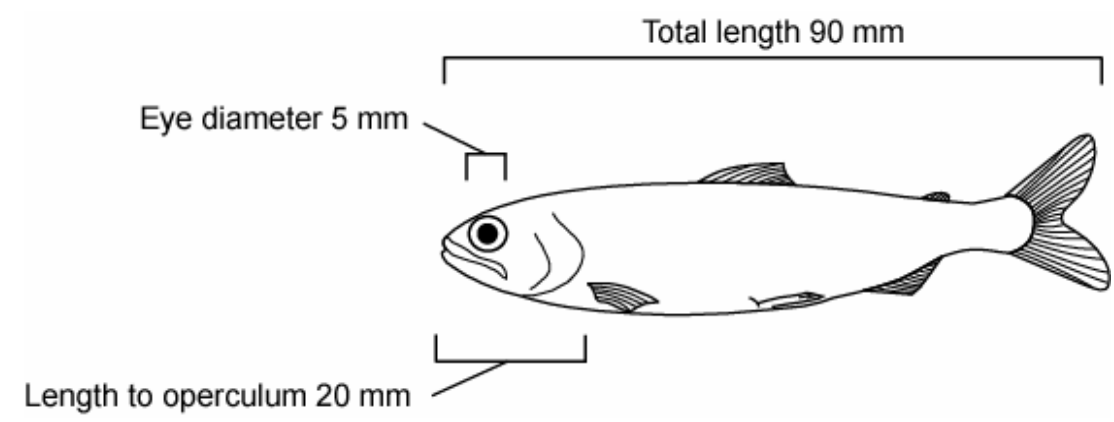

Figure 3.9. Average Size of Subyearling Chinook Salmon Smolt. Areas particularly sensitive to injury are near the head such as the eye and operculum.

Examples of tracking systems are provided below to clearly differentiate the types of data these systems collect in contrast to imaging systems. Tracking studies have been conducted at the U.S. Army Engineer Research and Development Center (ERDC) and at the dams. Studies conducted at ERDC's 1:25 scale physical models use neutrally buoyant plastic beads in place of fish. While these models provide information about potential fish routes (e.g., relative severity and nature of flow events) through the turbine the applicability of this information for understanding fish injury is limited by questions about the scalability of the beads and models to full-sized smolts and turbine units. Within the slower moving regions outside of the runner questions exist about whether fish with volitional control of their orientation would take different paths than the passive beads. And, obviously, the beads do not show the physical injuries that would be visible on live fish.

Tagging technologies used to track fish through the dams include radio telemetry and acoustic tags. Tagging requires a physical device be either attached to or implanted within a fish, and tags may be electronic or chemical. An external tag might be attached near the dorsal fin and transmit either an optical signal or an acoustic signal. Internal tags are commonly implanted either gastrically or within the peritoneal cavity of fish. Regardless of the attachment method, the signal that is transmitted from the tag must be received in this case on a stationary sensor or sensor array (e.g., affixed to structures within the dam). Both ultrasonic and light-emitting tag (LET) technologies have been examined for their role in tracking drogues and fish specifically throug turbines (Carlson et al. 2002). An example of the acoustic tag data is shown in the left-hand portion of Figure 3.10.

Another technology currently in use is fixed-location hydroacoustics. In this case, transducers ensonify and sample a portion of the water column continuously from a fixed location underwater. These systems uses low-power and high-frequency components specifically designed for work in and around turbines. One of these components is the split-beam transducer. These transducers contain phase information that allows for tracking of a fish's position through the sample volume. Smolt-sized fish can be tracked at far range (over $30 \mathrm{~m}$ ), and the equipment is designed to run continuously — months at a time. When run over an entire season, or during whole dam operations optimization tests, the results can be combined for a high power of discrimination. An example of hydroacoustic data within an intake is shown in the right-hand portion of Figure 3.10. Hydroacoustic sampling can track all the fish that pass through the system's sample volume although sample volumes are not very large, typically 6 to 12 degree nominal beamwidths. Telemetry on the other hand tracks fewer fish (only those that are individually tagged) but it can track those individuals over a longer range (e.g., a river reach) with the range only limited by the number of receiving sensors. 


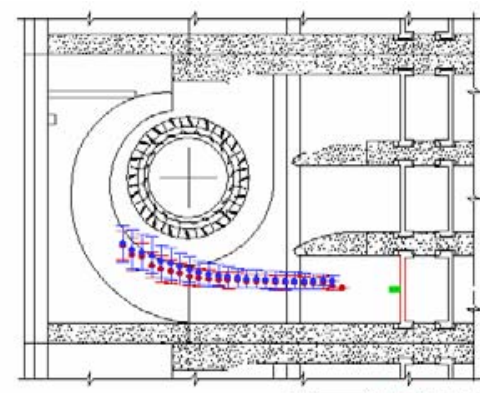

Drogue
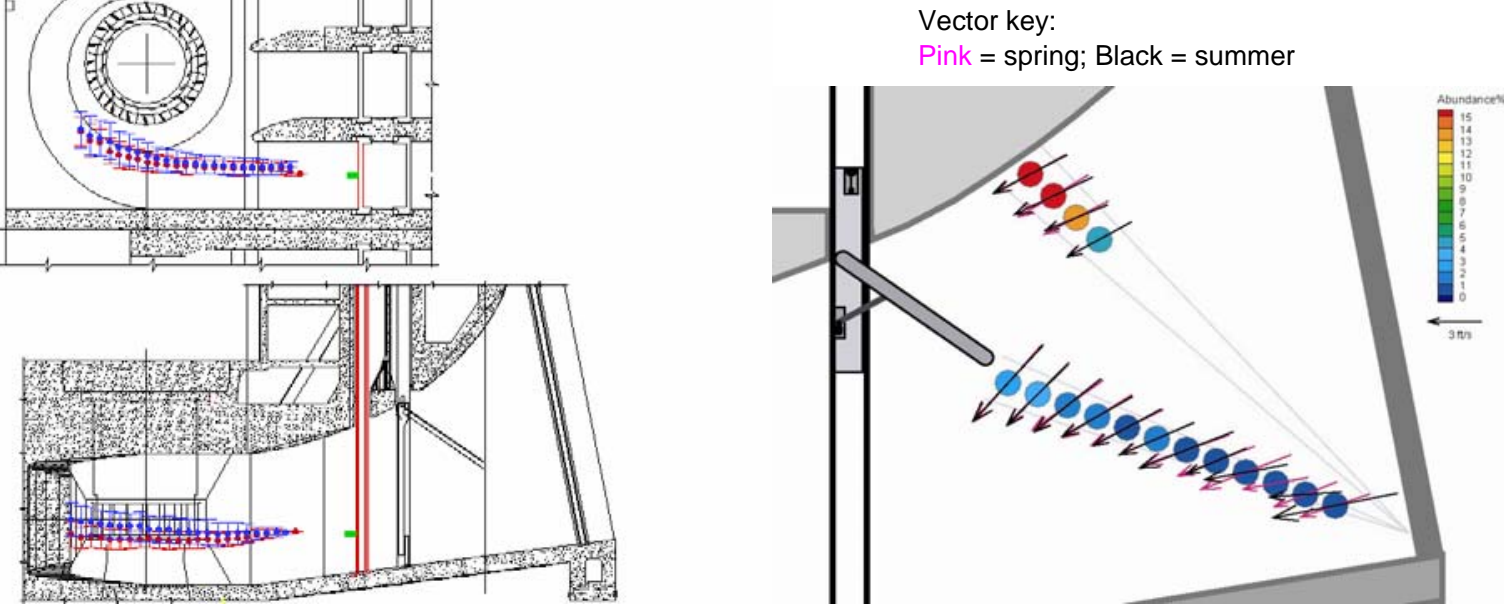

Figure 3.10. Tracking Technology Examples. Acoustic tag tracking example (left) from Carlson et al. 2002. Fixed-location hydroacoustic example (right) from Moursund et al. 2004.

At issue is the type of data that is provided by tracking systems. Tracking methods identify the location of a fish as a whole; they do not provide any indication of the location of individual parts of a fish. The sound pulse used in fixed-location hydroacoustic systems, for example, does not contain any information on a scale smaller than a fish length. Any tag tracking method is designed to specifically track the tag's location as a representation of fish location. Acoustic tags, for instance, are generally unable to resolve the spatial location of the signal to the scale of a fish. Even at a ping rate of 80 pings per second an acoustic tag would travel $2.5 \mathrm{~m}$ between detections at runner tip velocities, making strike detection probabilities low. A summary comparison of available turbine tracking and imaging technologies is shown in Table 3.1.

Table 3.1. Turbine Tracking and Imaging Technologies

\begin{tabular}{||c|l|c|c|c||}
\hline Range & \multicolumn{1}{|c|}{ Technology } & Deployment and Inference & Data Type & Resolution \\
\hline \hline \multirow{4}{*}{} & Acoustic Tags & Tag & Tracks & \\
\cline { 2 - 4 } & Light-Emitting Tags & Tag & Tracks & \\
\cline { 2 - 4 } & Hydroacoustics & Active & Tracks & \\
\cline { 2 - 4 } & Acoustic Imaging & Active & Images & \\
\cline { 2 - 5 } & Optical Imaging & Active & Images & \\
\hline
\end{tabular}

A further complication is that an underwater collision with a solid structure is not necessary for injury and is not easy to detect with tracking technologies. First, fish do not need to collide with a structure to necessarily cause injury. Shear studies have shown that hydraulic phenomena alone can induce severe injuries (Neitzel et al. 2003). Second, the soft-body collision of a fish or part of a fish against either a solid structure or fluid shear will not necessarily induce a change in trajectory of the body. Some energy will go into deformation of the soft tissues (e.g., stretching, tearing, or pulling). Some energy may go into rotational inertia. Neither of these energy-transfer events necessarily cause a deflection in the center of 
gravity of the fish. Thus, a very high-resolution tracking system would be able to identify and locate fish in relation to structure, but not the mechanism of injury other than perhaps a direct strike to the tag itself. Near-misses or near-hits would be difficult to detect without resolution less than a fish length, and the technological and logistic demands for tracking at that resolution are excessive.

Tracking technologies can define longer pathways than an imaging technology can and can provide data for the interpretation of fish passage risks in existing and redesigned turbines (Carlson et al. 2001; 2002). Pathway and trajectory information may be used to relate model data (both physical and computational) with data from injury studies to answer and/or predict turbine structural changes for fish. While this type of tracking data can determine the potential exposure to injury of fish passing through regions of a turbine, they cannot aid in determining the causal injury mechanism(s). Therefore, tagging technologies are not considered further in this report.

\subsubsection{Imaging}

Imaging technologies are differentiated by the physical phenomena sensed-acoustic (mechanical pressure wave) and optical (electromagnetic). The physics of signal generation, transmission, reception, and processing of these types of signals underwater are very different, so the advantages and disadvantages of these various traits are discussed separately.

\subsubsection{Acoustic Imaging}

While the acoustic tracking of fish has a relatively long history, acoustic imaging is relatively new. There are many systems that may be termed acoustic imaging systems, and which, under a variety of conditions, do produce images. A brief description of these systems is necessary to differentiate, and then select, likely candidates for the turbine environment.

In order of history, perhaps the oldest and most accessible acoustic imaging technologies are mechanical scanning systems. The side scan is a commonly used technique for bathymetery that uses mechanical scanning transducers pulled through the water on a tow body. As this tow body is pulled through the water, variations in the amplitude of the returns, along with a shallow grazing angle, show irregularities in bathymetry. Complete images can be pasted together and orthorectified using photogrammetry software in post-processing. Depending on the aspect, operating frequency, and tow rate, very fine details of bathymetry, rocks, and boulders can be clearly shown over hundreds of meters. Schools of fish can be detected but the side scan is not a good detector of individual fish or parts of fish because the fish's movements blur the image. Images are sensitive to the scan and tow rates and are easily distorted due to variations in tow body orientation and ground velocity. A related mechanical scanning system is the sector scan, which is a stationary system typically placed on end so that they scan up to $360^{\circ}$ in a horizontal plane from a stationary position. As the system scans, images of an area are generated. The resolution of the objects depends on the operating frequency and scan rate of the system. Sector scan systems are typically used to image structures and even divers at a construction or salvage scene. Images are updated with each scan, similar in process to scanning radar.

With increases in available processing hardware, multibeam sonar systems have become widely available. These are also used in swath bathymetry applications, but in a vertical deployment from a ship. Time blur is eliminated along the swath axis compared to the side scan. Again, the resolution of these systems is dependent on the operating frequency, ranges of interest, and platform and/or sensor motion. 
All of these systems can produce images of one sort or another, and all have been used to image fish schools for various applications (e.g., Gerlotto and Paramo 2003). Only one system comes close in terms of the spatial scale, operating frequency, and frame rate necessary for turbine-scale investigations: the dual-frequency identification sonar, or DIDSON (Moursund et al. 2003a).

The DIDSON is a dual-frequency multibeam acoustic lens-based sonar that has a field of view of $29^{\circ}$. At the highest frame rate and associated shortest range $(0.75$ to $5.25 \mathrm{~m})$, the DIDSON can achieve 20 frames per second (Belcher et al. 1999; Belcher et al. 2001). This ping rate limits deployments for fish detection to regions of the intake outside of the stay vanes and draft exit. For comparison with other acoustic methods, a split-beam transducer is simple and robust in harsh environments and commonly used for sampling fish at dams (Figure 3.11). The switching ability of both instruments (from transmitting to receiving) is very fast, but we still find that the two-way speed of sound in water limits acoustic methods in the very high velocity region of a turbine runner.

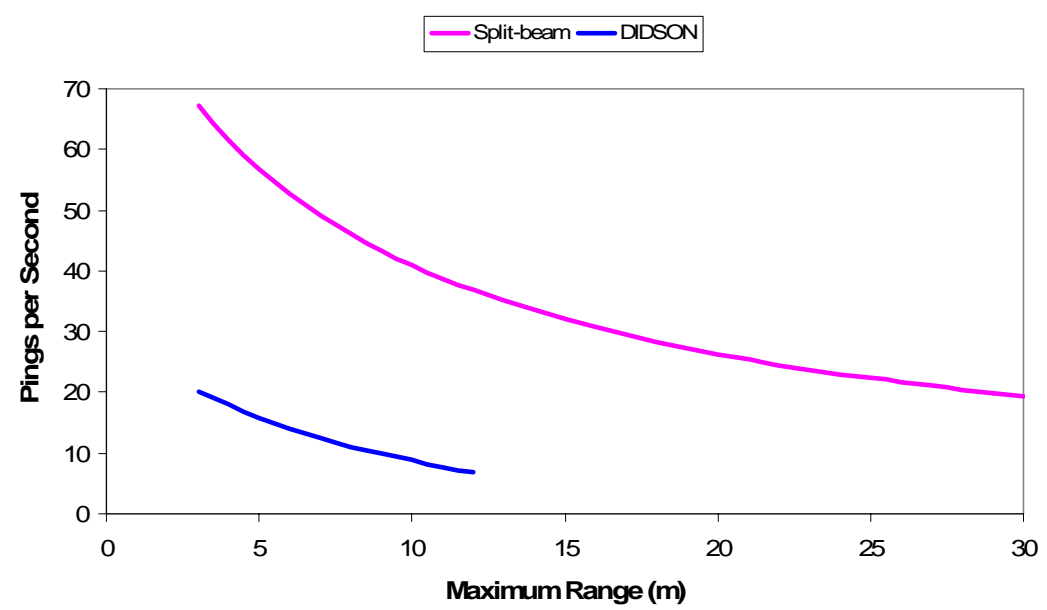

Figure 3.11. Maximum Range of Active Acoustic Tracking (split-beam) or Acoustic Imaging (DIDSON) Based on the Two-Way Travel Time of Sound Underwater and Hardware Limitations

While split-beam transducers do not produce images, the DIDSON multibeam array does so in real time and on a scale appropriate for certain fisheries investigations. For example DIDSON has been used to investigate gap loss and predation at The Dalles Dam J-occlusions, etc.; however, DIDSON's resolution is not clear enough for identifying injuries in small (subyearling) fish. The resolution of the system, as in all active acoustic systems, is range dependent. This resolution, however, becomes a more acute problem when the objective is to image fish for injuries. Frames from DIDSON footage collected at The Dalles Dam in 2001 and where both structural and fish components of the image are visible are shown in Figure 3.12. Only in the largest (adult) fish at the closest range are fin structures visible. The small fish, presumed to be juvenile salmonids, are only marginally identifiable as fish from a single frame (Figure 3.13). When viewed over time, the undulation of the bodies actively swimming against the current can be clearly made out and these objects are clearly identified as fish. However, the low resolution of the image makes it unsuitable as an injury-detection sensor at anything greater than $3 \mathrm{~m}$. 

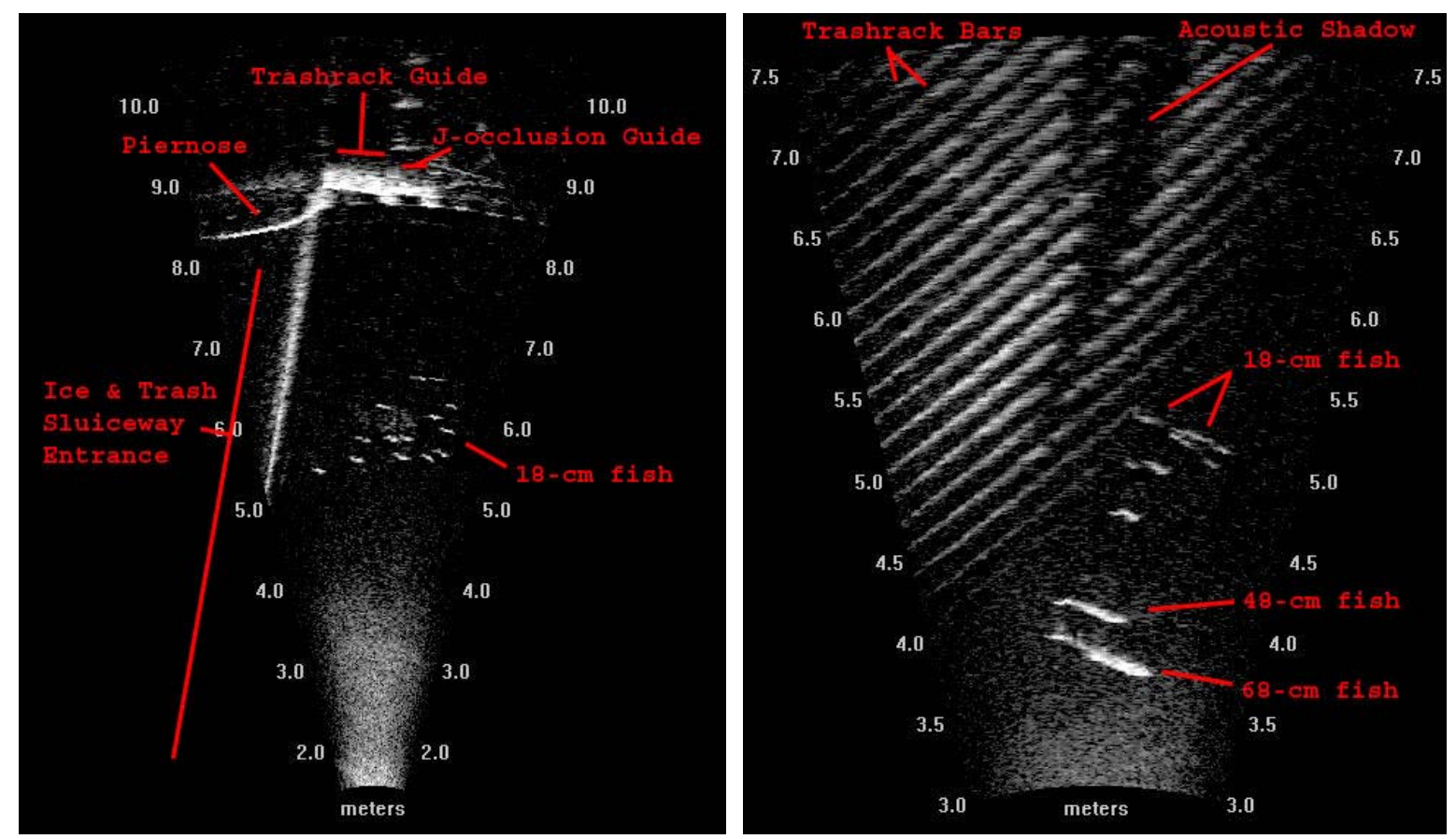

Figure 3.12. DIDSON Images from The Dalles Dam

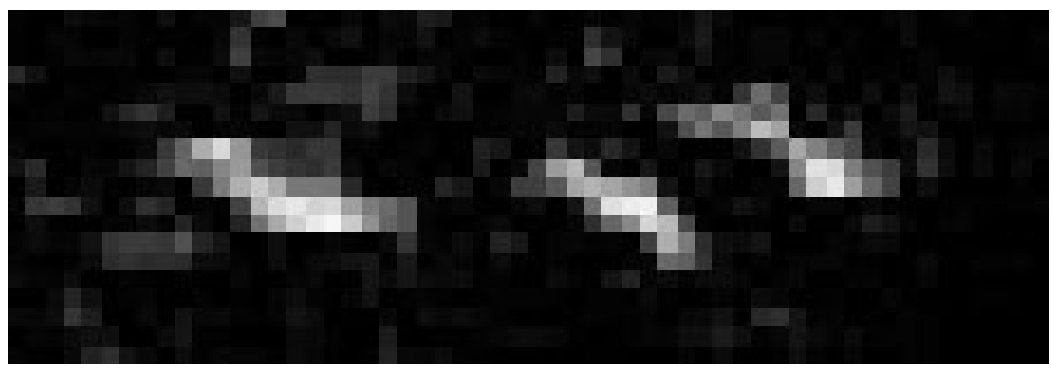

Figure 3.13. Zoomed Acoustic Images of What are Believed to be Three Yearling Chinook Salmon Smolts at $5.5 \mathrm{~m}$ Range from the Above Image at Left

\subsubsection{Optical Imaging}

Optics and optical (electromagnetic) systems remain standard tools for underwater research particularly oceanic research in low-turbidity water. However, the electromagnetic spectrum suffers much greater attenuation underwater than acoustics. It is the attenuation and susceptibility of light to interference from scattering that makes acoustic technology so attractive for underwater transmission. Optical imaging actually represents only the visible and near-visible range of the electromagnetic spectrum. Radio waves, for example, are still used to a limited extent in the underwater environment. Radio frequency tags are currently used in freshwater applications in the Columbia River basin and range from $30 \mathrm{MHz}$ to $175 \mathrm{MHz}$ (wavelengths of $10 \mathrm{~m}$ to $2 \mathrm{~m}$ ). However, the ability of radiowaves to spatially locate tagged fish is poor, on the order of tens of meters. Underwater attenuation is very high through the remainder of the electromagnetic spectrum with operating ranges below tracking feasibility for all frequencies in saltwater. 
Since no or very low levels of ambient light exist inside the turbine unit, this section is focused on active imaging systems (those that require external lighting). There are several types of optical imaging systems that have been developed recently, primarily for marine applications; these are of interest because they are usable in murky underwater environments. Many use lasers as a source of focused light in order to reduce backscatter. Light detection and ranging (lidar) systems, or laser-imaging radars, have been used for shallow water surveys for a number of years (Kamerman 1998). These are typically highpowered blue or blue-green lasers aimed downward from fixed-wing aircraft; they have been used for bathymetry of shallow waters or fishery surveys of surface-oriented pelagic fish (Gauldie et al. 1996). These systems create images from the movement of the platform, and are typically applied on much larger spatial and temporal scales than needed for this application. Due to their bulk and delicate instrumentation, it would be difficult to place them in a operating turbine environment.

A much more sophisticated lidar system is the laser line scan. Two systems, similar in both design and function, were originally built by Northrop-Grumman and by Raytheon. Science Applications International Corporation currently uses one for environmental surveys and underwater inspections. These are dual-scan systems in which both the laser transmitter and the receiving optics are mechanically scanned synchronously across a line. Both the laser and the receiving optics have narrow fields of view. As these scan, differences in elevation are recorded. As the sensor platform moves in a perpendicular direction, three-dimensional topography is depicted. This technology can be flown from an aircraft or underwater vehicle. The reason it works for murky underwater applications is the use of the laser to illuminate a very narrow portion of the target. This reduces the amount of scattering and increases the operational range beyond that of a broad illumination system.

An alternate lidar system is the streak-tube imaging lidar developed at Arete Associates. This system has undergone development for a shallow water mine countermeasures program for the Navy and has also passed initial deployment tests. It projects a fan beam laser perpendicular to the sensor's direction of travel, instead of a point source. The laser light is then received on a streak-tube receiver. The streaktube deflects the photons electronically, so this design has an additional advantage of no moving parts. Images are drawn based on both range and reflectivity to create three-dimensional imagery. As a general imaging system it is something like an inverted flying spot, but where a flying spot imaging system uses a narrow illumination beam and fixed optics, the streak-tube imaging lidar moves the optical receiver. Data specifications are 128 range and 512 azimuth pixel resolution at a sample rate of $400 \mathrm{~Hz}$.

One final type of lidar is the pulsed range-gate imaging lidar (Frouin and Gilbert 2002). The strategy for this type of system is to use a very accurate clock to time the distance traveled from the transmit pulse and range-gate (or blank out) the undesired transmit and received ranges. This optimizes reception for the range of interest by ignoring the light scattering between the source and the camera. The result is significantly enhanced contrast and clarity of images in murky water. One such system is the Magic Lantern $^{\mathrm{TM}}$ developed by the Kaman Aerospace Corporation. It was developed for the military and is flown from rotary aircraft for mine detection in shallow water. This system is actually wide-beam laser illumination and wide optical reception. The user selects the time/range domain window. Unfortunately, the range-gating technique assumes a knowledge of or operator adjustment of range to the target of interest. It is thus not suitable for the turbine-imaging scenario.

All of these lidar systems (laser line scan, streak-tube, range-gated) are beyond initial prototypes and are either in service or nearing field readiness. They all extend the range of optical imaging under murky conditions. They are also relatively delicate and bulky instruments that would not survive a turbine 
deployment. However, there are lessons to learn from these nearshore shallow-water imaging systems. They all have one thing is common: laser illumination. Only a laser-based system can produce enough light to penetrate depths beyond ambient light and have enough reflective energy to produce images from a moving platform.

A relatively simple underwater optical-imaging system would use focused lighting and fixed field of view underwater video cameras. An off-axis arrangement of lighting would improve the results by reducing scattering interference from the light source to the target. To go one step further, some imaging systems are capable of obtaining and analyzing three-dimensional images. There are readily available systems that automate the analysis of motion in three dimensions based on only two camera views (not necessarily orthogonal). The software is very good at locking onto and tracking relatively low-contrast parts of images and tracking with very good resolution (e.g., using built-in subpixel interpolation). These methods also increase the complexity of the equipment and require careful calibration of the scene prior to data collection. Scene calibration would be particularly difficult in the turbine environment because it would need to be done underwater due to changes in the refraction of light in air versus water at the lens interface. Finally, it is not clear that significantly more meaningful information would be obtained from this additional complexity based on motion analysis of the shear study results. A robust single off-axis high-speed camera with laser illumination is probably sufficient.

We can learn more from the recorded high-speed images of injury events in a recent laboratory shear study (Neitzel et al. 2000). These $320 \times 280 \times 8$-bit pixel images were taken at a recording rate of 500 frames per second under continuous lighting approximately $1 \mathrm{~m}$ from the subject. The shutter speed was the same as the record rate. The $3.5-\mathrm{mm}$ lens had a $25^{\circ}$ field of view which was $0.45 \times 0.45 \mathrm{~m}$ at the range of the fish (Figure 3.14). These were relatively large yearling Chinook salmon and had been selected to show expected injuries. Bodily details were difficult to distinguish on subyearling Chinook salmon at this resolution and clarity/contrast would have been enhanced if the lighting had been strobed rather than continuous; yet, injury events were successfully recorded and give us an idea of what a shear injury image would look like inside a turbine. These experiments were conducted with external lighting outside of the tank and with the clear water of a laboratory. Neither the absolute fish speeds (relative to the sensor) nor the turbidity were similar to conditions expected in the turbine environment. These additional factors, however, are addressed in the following section.
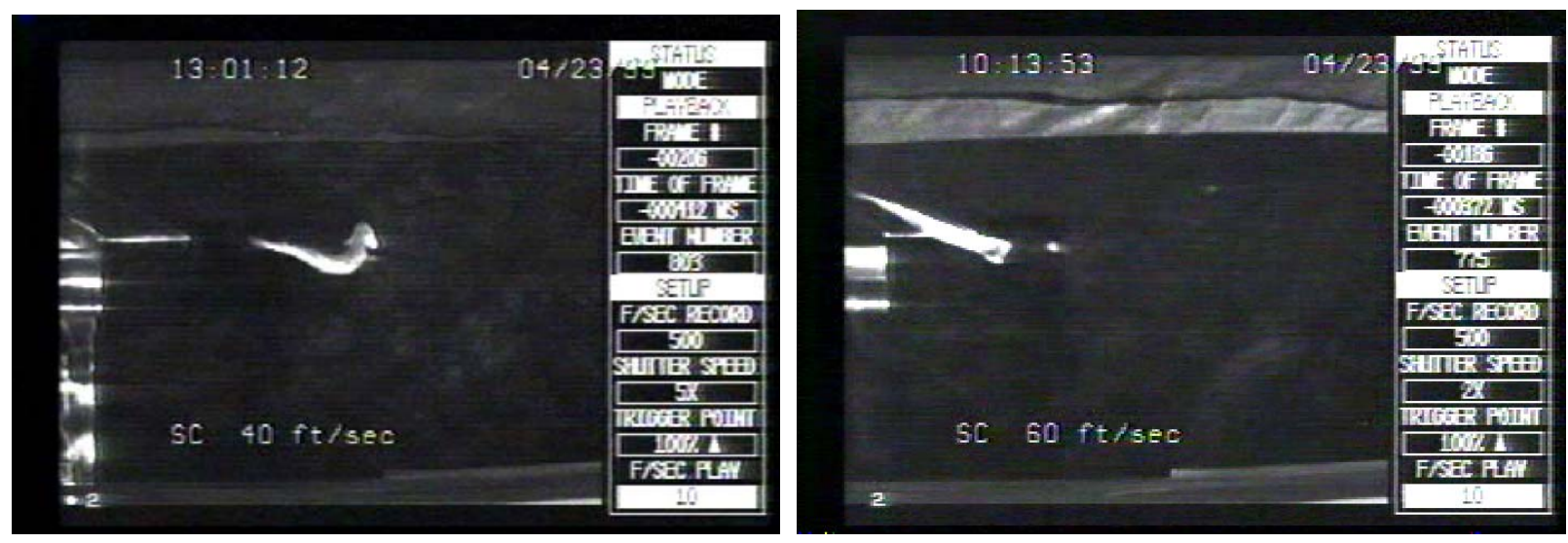
Figure 3.14. Photo of Laboratory Shear Tank Experiment. Image on left shows operculum flare as Spring Chinook salmon enters water jet. Image on right shows fish's eye has detached due to force of water jet.

\subsection{System Criteria}

The purpose of this section is to examine in detail, and quantify where possible, the criteria needed to image fish injuries in the turbine environment. Those criteria are used to make decisions based on factors that affect image quality. These factors, in approximate order of importance, are exposure time, frame rate, resolution, and range. Limitations, or the inputs into the constraint calculations, include the $90-\mathrm{mm}$ length of subyearling Chinook salmon smolt, image blur due to motion of the runner, and water clarity.

\subsubsection{Frequency}

The design basis for determining the frequency of an acoustic system in-turbine is that it must be above the level of ambient noise. The movement and vibration of mechanical pieces, the fish screen itself for instance, produce noise that is relatively low frequency. Cavitation from the runner produces very broad spectrum acoustic noise up to and including several hundred kilohertz. On one hand, this noise attenuates with range, with higher frequencies attenuating quicker. On the other hand, walls and other structures reflect sound and cause noise to reverberate within the confined space of the turbine unit. In this close proximity to the runner, the turbine unit is a very noisy acoustic environment. The DIDSON has two frequencies, 1.0 and $1.8 \mathrm{MHz}$, which are expected to be well outside the range of ambient noise. The small and dissolved particulate matter in river water that creates turbidity is visible with the DIDSON under certain conditions but it does not block an appreciable portion of the acoustic energy.

The optimal transmit frequency of an optical system requires a discussion of both absorption and scattering. The particulate matter component of a natural river causes light to be reflected and in the process multiple reflections are scattered. The amount of scattering depends on the quantity and composition of the suspended material. In terms of optical imaging, forward scatter, as light travels from the source to the target, reduces image contrast. Back scatter, as light from the target returns back to the sensor, reduces the sharpness or detail of an image. Thus both have measurable effects on image quality and reduction of these undesirable phenomena would be beneficial.

Pure freshwater and pure seawater exhibit similar absorption characteristics at visible wavelengths of the electromagnetic spectrum. Therefore the field of optical oceanography can provide much of the theoretical basis for any discussion of the behavior of light in water (Mobley 1994). There is a well known optical absorption minimum in the 380- to 500-nm wavelength portion of the spectrum. In the case of the riverine environment, dissolved organic compounds from upstream sources result in "yellow matter" that absorbs the shorter wavelengths, particularly blue. As reviewed under electromagnetic imaging, the transmission of visible wavelength light in ocean and coastal waters is an area of active sensor development. Nd:YAG (pronounced "neodymium-yag") lasers are the most common choice for sampling the coastal and nearshore environment. Nd:YAG stands for neodymium-doped yttrium aluminum garnet and the first, second, third, and fourth harmonic output wavelengths are 1,064, 532, 355, and $266 \mathrm{~nm}$. All of the flown ocean lidar imaging systems use diode pumped Nd:YAG blue-green lasers at $532 \mathrm{~nm}$. The argon ion (gas) laser also produces 488- and 514.5-nm wavelengths. Both are readily 
available from industrial sources and all take advantage of the optimal frequency for transmission of light through water.

\subsubsection{Frame Rate}

The goal of the frame rate of an imaging system is to capture all of the action. A frame rate that is too slow could miss important events, or worse, not detect the fish at all. A frame rate that is too high would waste resources by oversampling. In order to calculate a sufficient rate to capture images, the anticipated target characteristics are applied. The events of interest may be assumed to be a function of fish length. The residence time between the stay vanes and runner is perhaps $0.2 \mathrm{~s}$ ( $\mathrm{s}$ is a back-of-the-envelope calculation that considers a target traveling at $15 \mathrm{~m} / \mathrm{s}$ over a distance of $3 \mathrm{~m}$ ). We'll also assume a simple linear trajectory in front of the camera. A general form of such an equation is given below (Equation 1).

Equation 1. Generalized frame rate calculation based on target characteristics.

$$
\text { Minimum Frame Rate }=\frac{\text { Target Velocity }}{\text { Distance Traveled Between Frames }}
$$

where Target Velocity in this case is assumed to be the runner speed, and

Distance Traveled Between Frames is $1 / 4$ body length of a $90-\mathrm{mm}$ subyearling Chinook smolt

For example, the runner tip velocity can be used as an appropriate surrogate of the target velocity of interest. It will be important to capture a time series of the runner as it interacts with fish. The runner tip will be traveling at approximately $32 \mathrm{~m} / \mathrm{s}$. The distance that the runner tip travels between frames is based on the length characteristics of the target of interest. For this example, $1 / 4$ body length of a $90-\mathrm{mm}$ subyearling Chinook smolt is used. Because the runner tip has the highest velocity along the runner and because $90 \mathrm{~mm}$ is a small length for a juvenile salmonid, these factors represent the worst-case scenario for imaging performance.

Given that most injuries occurr in the head region, the imaging criteria will be based on detecting events based on that scale. The linear distance from the tip of the nose to the operculum on a typical smolt is approximately $25 \%$ of the body length. Should an eyeball avulsion take place, for instance, we can assume that it will be imaged within a head length. Other events, such as decapitation, should be obvious over several frames. The frame rate calculations are based on imaging one frame every onequarter body length of a 90-mm subyearling Chinook salmon smolt. As the results in Figure 3.15 show, at the runner tip the frame rate requirement approaches 1,500 frames per second. This estimate is the most extreme case of a very small fish passing near the runner tip. Figure $\mathbf{3 . 1 5}$ shows graphically the decreasing frame rate requirements of other locations within a turbine unit.

\subsubsection{Flash Exposure}

Since the blade is moving the same speed as or faster than the fish through the runner region, we need to avoid motion-induced image blur of the runner tip in order for images to be interpreted. Pictures where the image of the runner is blurred, even if the fish is not, would be useless because the physical relationship between the runner and the fish would be blurred. The major questions of interest regarding the causal mechanism(s) of fish injury require detailed data on the relationship of the fish when injury occurs in relation to the runner or any other structure. If those images are blurred, then the relative 
contribution of hydraulic and mechanical forces to injuries cannot be determined. Therefore, the maximum velocity is used in the following calculations as a conservative estimate. The velocities of the runner tip represent the maximum velocities to be encountered and the greatest challenge for an imaging system. Greater imaging system performance would be expected in areas of slower absolute velocities.

A common technique in the field of high-speed photography is the use of a strobe to shorten exposure times and reduce motion-induced blur (Sidney 2002). As increasingly higher speed photographs are desired, the physics of mechanically moving the film behind the lens becomes limiting. After that, at some point the mechanics of opening and closing the shutter becomes limiting. Last to be limited is the flash system where various methods have been developed to produce a particularly short and intense light exposure. Exposures shorter than 1/1000 s may be defined as classical high-speed photography. The basic sequence of events of a high-speed camera system is as follows: 1) the camera opens the shutter, 2) the flash triggers, 3) the shutter closes, and 4) the film advances. It is typical to provide a dark scene so that no extraneous light enters the camera housing during the relatively long shutter period. The turbine unit environment is conveniently dark for using such a technique.

One method to determine an optimal exposure time is based on the concept of maximum allowable blur of a portion of the subject. The formula also takes into account the direction of subject motion; however, if we assumed that the target is moving perpendicular to the film plane, then the cosine function disappears (Equation 2). The image quality constant adjusts amount of blur or quality of the selected smallest detail.

Equation 2. Exposure time based on minimum blur of subject of interest.

$$
T=\frac{\text { size of smallest detail within subject }}{\mathrm{K} \square \mathrm{u}_{\text {target }} \square \cos (\alpha)}
$$

where $\mathrm{K}$ is an image quality constant (generally from 2 to 4 )

$\mathrm{u}_{\text {target }}$ is the target velocity, in this case the maximum fish/runner velocity

$\alpha$ is the angle between film plane and subject direction.

If we apply this formula to a 5-mm (i.e., an eye diameter) sized object, quality constant of 4, and 0-deg approach angle, the exposure time at a $32 \mathrm{~m} / \mathrm{s}$ runner should be about $4 \times 10^{-5} \mathrm{~s}$ or about $40 \mu \mathrm{s}$. Therefore, in this worst-case scenario of runner tip exposures, the flash exposure should be on the order of $40 \mu \mathrm{s}$. Also, given the frame rate calculations from the previous section, it is apparent that the frame rate and exposure are inversely related. This relationship is illustrated in Figure 3.15. 


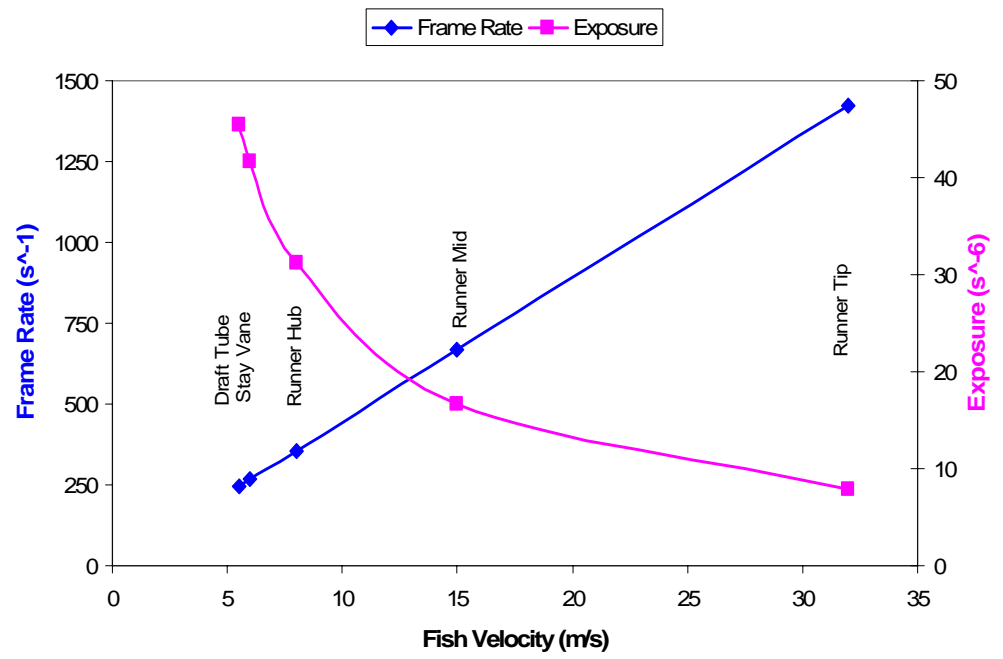

Figure 3.15. Frame Rate and Exposure Time by Turbine Region (Target Velocity). Based on onequarter body length of a $90-\mathrm{mm}$ subyearling Chinook salmon smolt and $1 \mathrm{~mm}$ of acceptable blur.

\subsubsection{Detectability and Field of View}

In most classical high-speed photography applications, the location of the subject matter is not only known, but well planned in terms of lighting, frame rate, and triggering. In the case of turbine imaging, we do not have such an advantage. The purpose of this section is to quantify the relation between several factors that determine the ability of a system to detect smolts in the runner region. This will be an important aid in determining optimal hardware for an imaging system such as the field of view characteristics. Detectability for these calculations is defined as the number of frames of images recorded. In reality, detectability is a function of target speed, the imaging system's field of view, and sample rate (Equation 3). Detectability declines with a decreasing field of view represented by different lens fields of view (Figure 3.16). The sample rate has been, in part, determined by the target characteristics and frame rates in the previous sections. In this example, a camera with a $60^{\circ}$ lens would still get 15 images at $0.3-\mathrm{m}$ range at the runner tip.

Equation 3. Detectability of fish targets through a field of view.

$$
\text { Detectabilty }\left(\# \text { of frames) } \equiv \frac{\text { linearized field of view }(\mathrm{m})}{\operatorname{target} \text { velocity }\left(\mathrm{m} \cdot \mathrm{s}^{-1}\right) / \operatorname{sample} \text { rate }\left(\text { frames } \cdot \mathrm{s}^{-1}\right)}\right.
$$




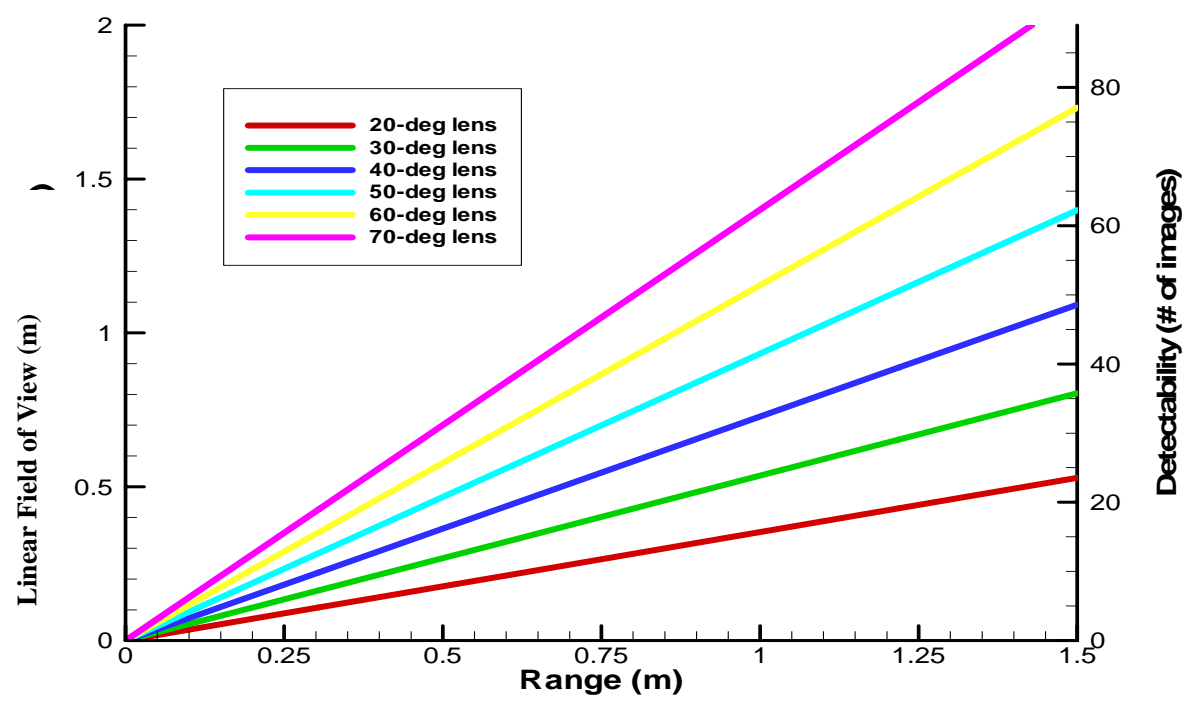

Figure 3.16. Linear Field of View and Detectability vs. Range by Lens Field of View

\subsubsection{Resolution}

The resolutions of all the candidate technologies described are range dependent. This is true for optical systems in which images are captured through a lens onto a fixed grid and also for acoustic systems which are polar coordinate devices by nature. Resolution is a product and a function of range, imaging element, and lens. For technology comparison purposes, resolution is quantified as the size of a pixel for optical systems or nominal half-power beamwidth for acoustic systems. To meet the turbine imaging purpose, the system must not only be able to image the parts of the fish susceptible to injury, but must also do so at a variable range of interest. Too little detail would literally blur the distinction of injury types during an event, while too narrow a field of view would have a low probability of detecting events. A larger imaging element allows for details to be discerned at longer ranges, but there are limitations in the size of manufactured elements. An arbitrarily chosen $60^{\circ}$ field of view was selected to illustrate the relationship between range and resolution by different typical optical element resolutions (Figure 3.17). For comparison, DIDSON acoustic imaging resolution at $1 \mathrm{~m}$ range is about $5 \mathrm{~mm}$, and the $29^{\circ}$ field of view is only $0.5 \mathrm{~m}$ across.

Expected limitations in underwater visibility restrict the maximum useful range of optical solutions. Further, the forward scattering of light will reduce image contrast and backward scattering will reduce image sharpness or resolution. Thus Figure 3.17 below indicates the trends with resolution, but cannot be used to accurately predict performance under murky river conditions. Another complication stems from the inability to predict these effects quantitatively because they are dependent on the chemical and particulate composition of the water in question. These light-scattering properties of water are generally addressed with direct measurement methods. 


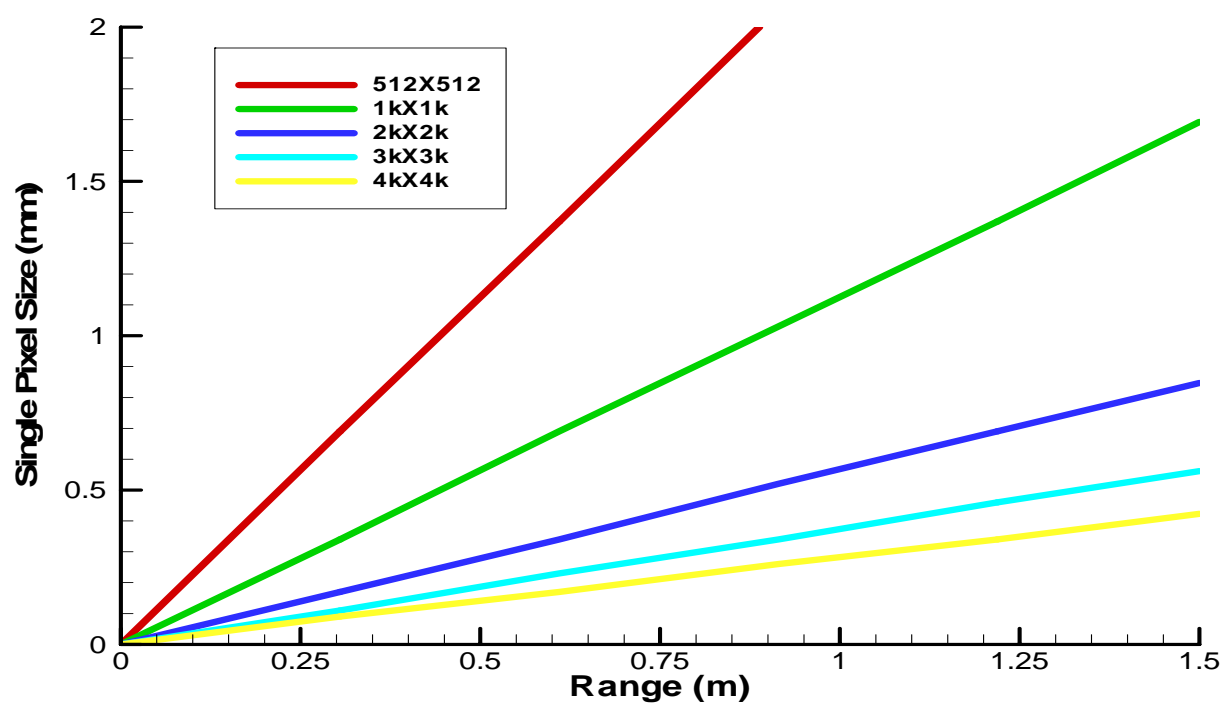

Figure 3.17. Single Pixel Size ( $\mathrm{mm}$ ) vs. Range by Sensor Resolution. This assumes a $60^{\circ}$ field of view and ideal water clarity.

\subsubsection{Range}

The treatment of range in this analysis has been given the least priority and weight of the system criteria. This was based on a decision early in the technology assessment on the necessity of making tradeoffs between range and imaging system performance. System performance was keyed primarily on the image quality needed to determine fish injury. This basic level of information was the driving goal of the study, since no amount of data would be useful if it could not support the imaging goal at any range. The maximum operating range became essentially a dependent variable to the imaging criteria discussed above.

\subsubsection{Tank Trials}

To begin to address some of the uncertainties with the above calculations and effects, particularly the effects of turbidity on resolution, a small laboratory-scale experiment was conducted. In this case, because of the variability in the chemical and particulate constituents of rivers, there is no theoretical basis for predicting the effects of scattering on an optical imaging system's performance. Performance, or image quality, will degrade in the presence of turbidity. These laboratory experiments address how much it will be degraded and to what extent it can be degraded and still collect useful data. To accomplish this, reproductions of typical low-visibility spring-freshet riverine water conditions were assembled together with some of the expected optical system components of a high-speed imaging system.

At the higher visibility levels (1.25 Secchi $\mathrm{m}$ ), enough light reached the target to be identifiable even at $1.5 \mathrm{~m}$. The critical components of the fish such as the eye and operculum can be defined at this range given sufficient resolution. At 0.75 Secchi $\mathrm{m}$ visibility, scattering from the dissolved and particulate matter had reduced the available light to render the fish barely detectable at $1.5 \mathrm{~m}$ (Figure 3.18). More importantly, this additional scattering reduced the detail available in the image. The blurring of the images due to backscatter has an effect similar to decreasing the effective resolution. This effect has the potential to reduce fish detail to the point of not being able to distinguish the fish body/head parts that are 
critical in determining the mechanism of injury. In this trial, at distances of 0.6 and $0.9 \mathrm{~m}$ from the light source, fish body parts show clearly and would be sufficient for injury detection-even under extremely poor visibility conditions.
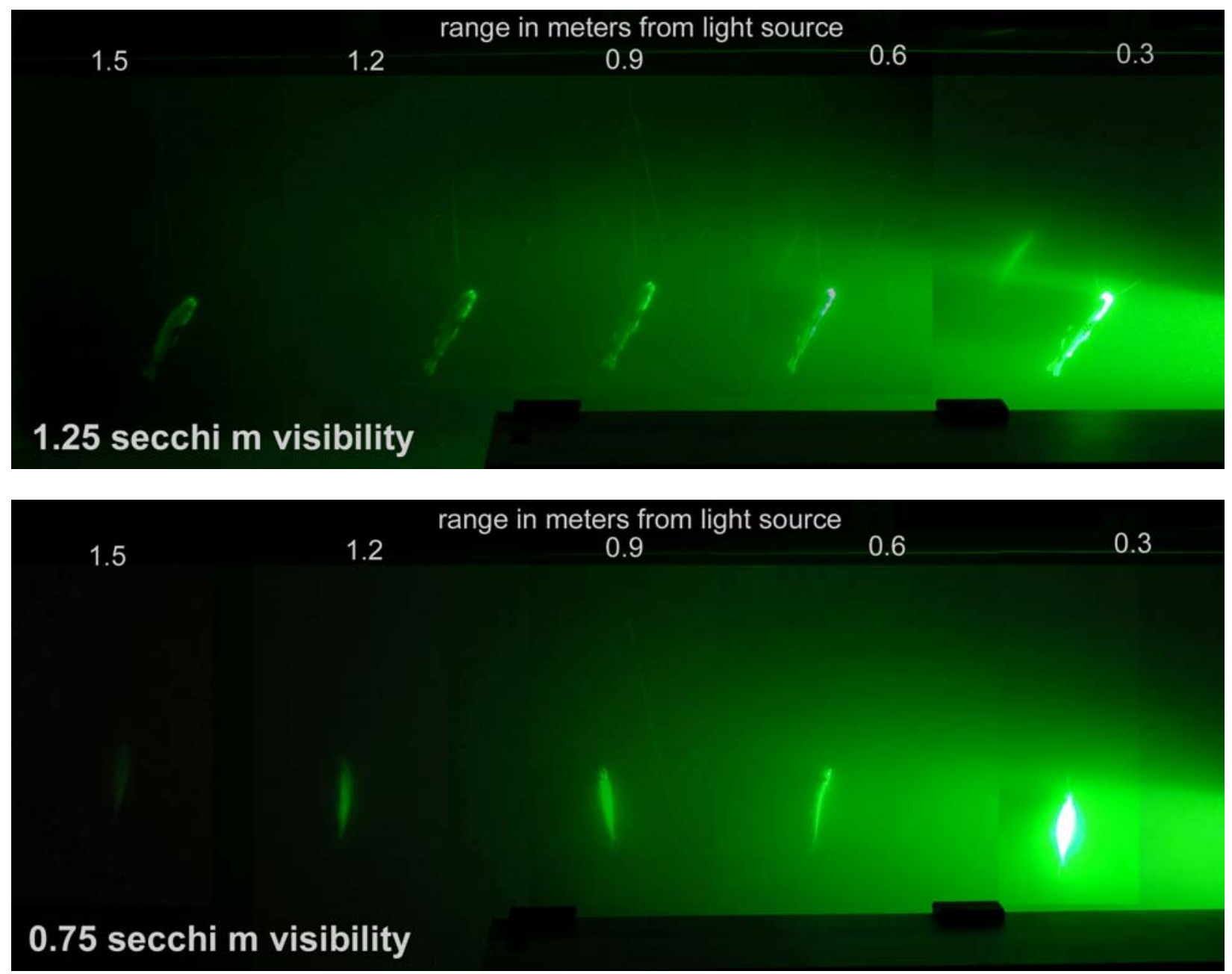

Figure 3.18. Images of a Subyearling Chinook Salmon at Ranges from 0.3 to $1.5 \mathrm{~m}$ from the Laser Light Source on the Right-Hand Side of the Tank with a Visibility of Only 0.75 and 1.25 Secchi m. All images are of the same fish.

One unexpected detail was the problem of too much light close to the source. The laser is so intense that the exposure latitude of the camera was exceeded and the image was washed out. This was information lost; the detail needed for fish injury was gone and no amount of digital darkroom adjustments could bring that information back. The result is potentially not being able to distinguish the portions of the fish critical for injury mechanism studies very close to the light source. On the other hand, an actual deployment would expect very low probabilities of detection at that range.

This test also demonstrated the importance of an off-axis light source. As in marine applications, light is scattered both as it is transmitted from an external light source and on its return trip to a camera or other receiver. The former reduces the contrast; the latter reduces clarity. Scattering due to murky river conditions will limit both the range of detection and image resolution to very short ranges depending on 
the time of year and the particular river. The exact amount of image degradation caused by turbidity is difficult to predict, but can be simulated. Figure 3.19 shows images of the fish at $0.9-\mathrm{m}$ distance with 0.75 Secchi $m$ of visibility. They have been rotated clockwise and gray-scaled to simulate output from a monochromatic optical video camera, but are not otherwise enhanced for contrast. Each one has a subsample of the original picture to the specifications shown in Table 3.2. On the far right image, the eye and operculum are indistinct. This can be caused by a low sensor resolution, scattering, or both. In this case, the effect of resolution is demonstrated. It is also worth noting that the middle resolution image contains sufficient information to discern the eye and head region. Higher-than-necessary sensor resolutions would waste resources in both capital equipment and storage.

Table 3.2. Image Resolution Subsampling

\begin{tabular}{||l|c|c|c||}
\hline & $\begin{array}{c}\text { Megapixel } \\
\text { Equivalent }\end{array}$ & $\begin{array}{c}\text { Example Camera } \\
\text { Resolution }\end{array}$ & $\begin{array}{c}\text { Actual Subsample } \\
\text { Resolution }\end{array}$ \\
\hline \hline Left & 1.0 & $1024 \times 1024$ & $117 \times 51$ \\
\hline Middle & 0.5 & $700 \times 700$ & $88 \times 41$ \\
\hline Right & 0.25 & $500 \times 500$ & $61 \times 29$ \\
\hline
\end{tabular}
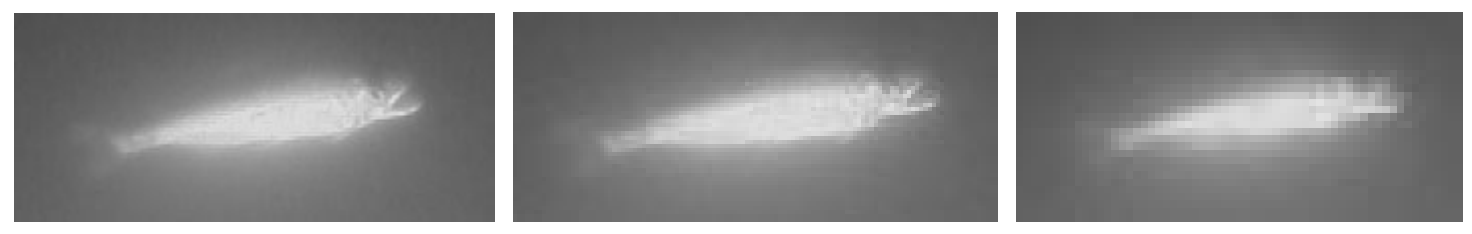

Figure 3.19. Approximately 1 (left), 0.5 (middle), and 0.25 (right) Megapixel Images of the Subyearling Smolt at $0.9 \mathrm{~m}$ Range and 0.75 Secchi m of Visibility

This was admittedly an imperfect test. These photographs were taken perpendicular to the tank where the light reaching the camera traveled through air, not murky water. A truer test would require a very large square tank in which light travels to the target and to the camera in turbidity which might be obtained easier in a gate well than a laboratory. Considering the expense and inaccessibility of an inturbine deployment, it would be useful to expand to a gate well-scale demonstration to measure more variables such as the degree off-axis, transmit intensity, fan beam width, and receiving camera parameters (focal length, shutter speed, aperture).

Another interesting aspect of these tests was that the system is more likely to be scattering-limited than absorption-limited. If the detection range is limited and scattering is limited, then a sub-optimal transmission frequency could be used. In this case, there is compelling rationale for using non-visible spectrum lasers. First, fish would not alter their behavior in the presence of it; second, sensitivity of the imaging elements may actually be increased by using a longer wavelength light source just by the nature of certain charged-coupling devices. Nd:YAG lasers are relatively compact, robust, and commonly available. The first harmonic Nd:YAG output is in the infrared at 1,064 nm. Use of this frequency will be investigated further for a second-phase report that will describe equipment specifications for an inturbine deployment in detail. 



\subsection{Discussion}

This technology assessment has providedthe explicit definition of the scale of the research problem. All of the technological solutions explored were for the objective of observing the causal mechanisms of injury to juvenile migratory fish within an operating Kaplan turbine unit. Thus, the first half of this effort was to define as completely as possible what that environment is and how much is known about fish injury to date. Information from both in-situ and ex-situ experiments has shown that fish do not need to actually contact a solid surface to be injured. Moreover, the scale of these injuries is on a scale smaller than the length of a fish. Eye injuries, for instance, may be on a scale of only $5 \%$ of total fish length yet are critical for fish survival.

There are a variety of technological solutions that could be used to evaluate fish behavior. In general, these technologies have been divided by the type of data they provide: tracks versus images. Any of the tracking technologies can be used to determine where your fish went. In contrast, imaging systems can be used to determine what happened at a specific location. The following conceptual model illustrates the tradeoffs that must be made between each type of solution (Figure 4.1).

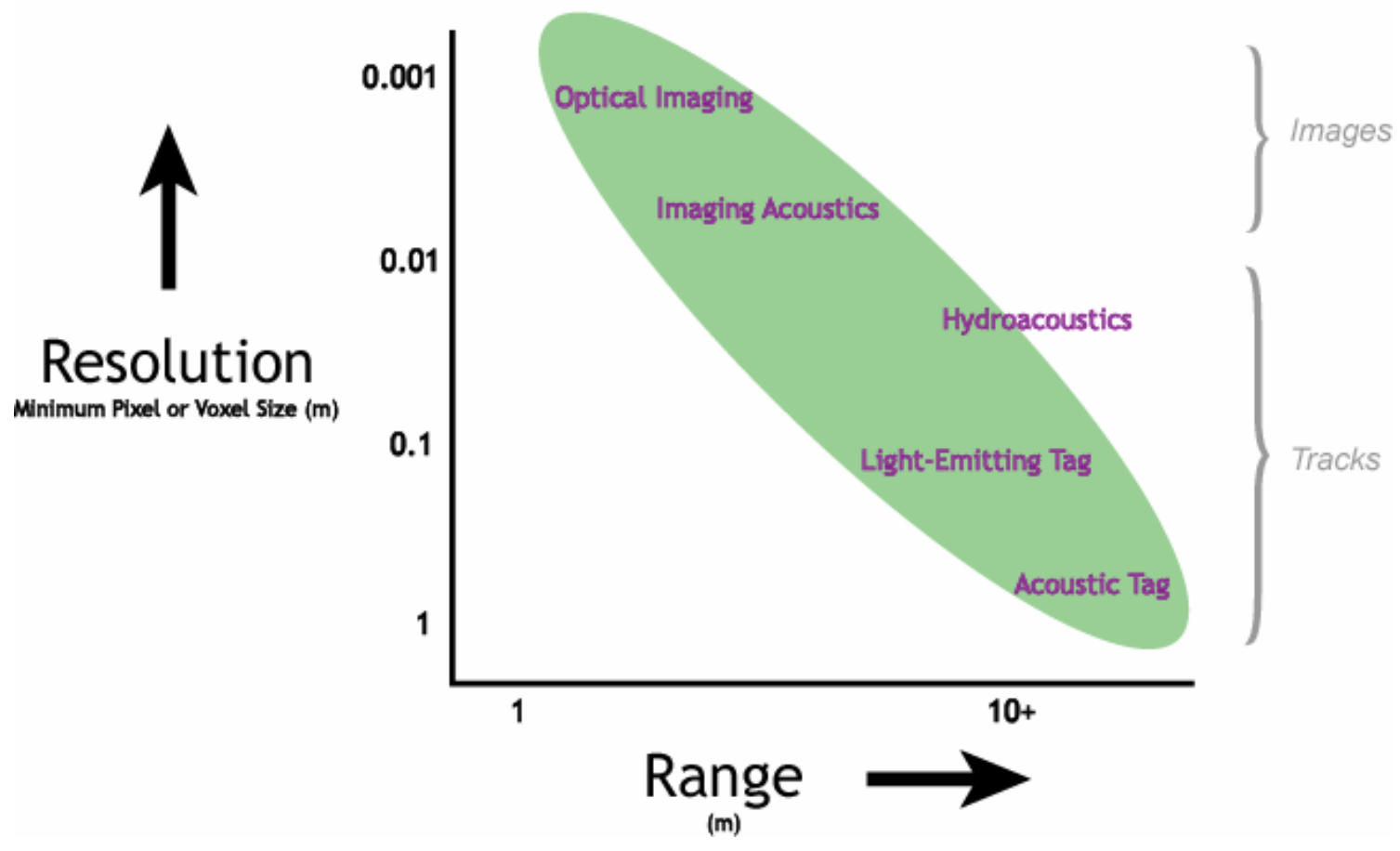

Figure 4.1. Turbine Tracking and Imaging Technologies Showing Tradeoffs between Range, Resolution, and Data Type Shown

For any imaging system the goal is to create a time series with sufficient resolution to discern the fish, or part of a fish, that is impacted by the turbine environment. Two factors primarily constrain the equipment needed to observe the approach and interaction of fish with turbine elements: frame rate and resolution. At the runner tip, a very fast frame rate and very short flash exposure is needed.

Instrumentation characteristics on this scale are found only under high-speed photonic techniques. The relatively low resolution and low frame rate of acoustic imaging are insufficient for the detection of fish 
injury at the runner region (Table 4.1). Under certain circumstances, however, the tradeoffs with range can become acceptable. For example, acoustic imaging may be useful in situations that involve larger targets (e.g., adult salmonids) and/or slower rates of motion.

Table 4.1. Relative Performance Features of Acoustic versus Optical Imaging

\begin{tabular}{|l|c|c|c||}
\hline & Range & Frame Rate & Resolution \\
\hline \hline Acoustic & Long & Slow & Low \\
\hline Optical & Short & Fast & High \\
\hline
\end{tabular}

After frame rate and resolution, the next criterion becomes the flash exposure. Because of the requisite frame rates and exposures, only laser light is expected to provide sufficient illumination over extremely short time intervals. The high-intensity short-interval pulse will freeze the motion of the subject in time and will maximize the detail available for image interpretation. At a tertiary level, another variable to consider is the detectability of targets. To complicate matters, tradeoffs must be made between factors such as the maximum operating range, field of view, sensor element resolution, and detectability. A narrow field of view results in better resolution at longer ranges but poorer detectability close to the sensor. A wide field of view results in the converse: better detectability at shorter range but limited distance resolution. Deployments of an optical system will require site-specific and even perhaps injury-specific design.

While tank trials simulated performance under poor visibility conditions of a river such as the Columbia or Snake, additional areas of investigation in deployment remain. An optical system must still answer how far off-axis from the light source is optimal or possible in a Kaplan turbine. Cameras and lighting must be able to withstand the rigors of deployment inside the turbine. The potential also exists, if scattering and not attenuation is limiting, to look at alternate transmission frequencies. A frequency outside the visible reception of fish would eliminate any possibility of the light source modifying the fish's behavior as they approach the sample volume. 


\subsection{Conclusion}

Imaging alternatives have been identified and evaluated both theoretically and in limited laboratory trials for observing the causal mechanisms of injury to juvenile migratory fish within an operating Kaplan turbine unit. The spatial relationship between the fish, the runner, gap, hub, and other structures present were established along with expected maximum velocities. For the runner region, the limiting (maximum) velocity is not actually the fish but the runner tip. Even though from a relative perspective the fish will not experience these velocities, the image will have to include the runner if mechanisms are to be identified.

High-speed optical imaging was the only technology feasible for imaging fish fast enough and at high enough resolution to detect strike/collision and operculum and eye injuries at the runner tip. Further, a laser light source is required to produce enough light in the extremely short exposure for preventing image blur from the fish or runner moving at $32 \mathrm{~m} / \mathrm{s}$ or so through the tip region. Optical wavelength scattering due to murky river conditions could limit the range of detection and image resolution to very short ranges $(<1.5 \mathrm{~m})$, depending on the time of year and the particular river.

High-powered lasers and optical sensors are a workable solution. Given the needs and constraints of observing fish as they pass through an operating turbine unit, a pulsed-laser optical system is the best available and foreseeable technological solution. This system will work during the typical low-visibility conditions that exist during the spring freshet, which is also the period that most fish migrate downstream. Additionally, this type of equipment can be built to withstand the rigors of the turbine environment. Even though the imaging requirements discussed refer specifically to the runner region, these methods may be easily translated to other regions within a turbine with a reduction in technological requirements. A system designed to function near the runner tip will work at all other regions of a turbine unit.

This technology assessment has shown that a high-speed optical imaging system within an operating turbine unit is a realistic solution using commercially available components. Acquired data from field deployments of an imaging system for fish injury detection will create opportunities for industry to modify turbines and improve fish passage conditions. For instance, the in-situ imaging of fish injury could be combined with in-situ tracking, physical modeling, and numerical simulations in order to realize the full potential of the data. Fish injury data combined stochastically with turbine models and fish tracking/distribution data would an important part of the fish-friendly turbine designer's toolkit. 



\subsection{References}

Abernethy CS, BG Amidan, and GF Čada. 2002. Simulated Passage through a Modified Kaplan Turbine Pressure Regime: A Supplement to "Laboratory Studies of the Effects of Pressure and Dissolved Gas Supersaturation on Turbine-Passed Fish.” PNNL-13470-A, Pacific Northwest National Laboratory, Richland, Washington.

Abernethy CS, BG Amidan, and GF Čada. 2001. Laboratory Studies of the Effects of Pressure and Dissolved Gas Supersaturation on Turbine-Passed Fish. DOE/ID-10853, prepared by Pacific Northwest National Laboratory, Richland, Washington, for the Advanced Hydropower Turbine Systems Team, U.S. Department of Energy, Idaho Falls, Idaho.

Belcher E, B Matsuyama, and G Trimble. 2001. "Object Identification with Acoustic Lenses.” In Proceedings of Oceans 2001 Conference, pp. 6-11, Marine Technology Society, Washington, D.C.

Belcher E, H Dinh, D Lynn, and T Laughlin. 1999. "Beam Forming and Imaging with Acoustic Lenses in Small, High-Frequency Sonars." In Proceedings of Oceans 1999 Conference, pp. 1495-1499, Marine Technology Society, Washington, D.C.

Bouck GR, and SD Smith. 1979. Mortality of Experimentally Descaled Coho Salmon (Oncorhynchus kisutch) in Fresh and Salt Water. Transactions of the American Fisheries Society 108:67-69.

Čada GF, MG Ryon, DA Wolf, and BT Smith. 2003. Development of a New Technique to Assess Susceptibility to Predation Resulting from Sublethal Stresses (Indirect Mortality). ORNL/TM-2003/195, prepared by Oak Ridge National Laboratory for the Office of Energy Efficiency and Renewable Energy, Wind and Hydropower Technologies, U.S. Department of Energy.

Čada GF, CC Coutant, and RR Whitney. 1997. Development of Biological Criteria for the Design of Advanced Hydropower Turbines. DOE/ID-10578, prepared for the Office of Geothermal Technologies, U.S. Department of Energy, Idaho Falls, Idaho.

Carlson TJ. 2001. Proceedings of the Turbine Passage Survival Workshop, Portland, Oregon. PNNL-SA-33996. Pacific Northwest National Laboratory, Richland, Washington.

Carlson TJ and MA Weiland. 2001. Light-Emitting Tag Testing in Conjunction with Testing of the Minimum Gap Runner Turbine Design at Bonneville Dam Powerhouse 1. PNNL-13415, Pacific Northwest National Laboratory, Richland, Washington.

Carlson TJ, MA Weiland, VK Sutton, AR Wirtz, M Macaulay, and JR Skalski. 2002. Ultrasonic 3-D Tracking of Fish and Drogues Passing through a Kaplan Turbine Intake at McNary Dam, 1999 \& 2000. PNWD-3128, prepared for the U.S. Army Corps of Engineers, Walla Walla, Washington.

Frouin RJ and GD Gilbert (ed). 2002. Ocean Optics: Remote Sensing and Underwater Imaging: Proceedings of the International Society for Optical Engineering. Volume 4488, August 1-2, 2001, San Diego, California. The International Society for Optical Engineering, Bellingham, Washington. 
Gauldie RW, SK Sharma, and CE Helsley. 1996. "LIDAR Applications to Fisheries Monitoring Problems." Canadian Journal of Fisheries and Aquatic Sciences 53(6):1459-1468.

Gerlotto F and J Paramo. 2003. "The Three-Dimensional Morphology and Internal Structure of Clupeid Schools as Observed Using Vertical Scanning Multibeam Sonar." Aquatic Living Resources 16(3):113-122.

Kamerman GW (ed). 1998. Laser Radar Technology and Applications III: Proceedings of the International Society for Optical Engineering. Volume 4488, April 14-16, 1998, Orlando, Florida. The International Society for Optical Engineering, Bellingham, Washington.

Mobley CD. 1994. Light and Water: Radiative Transfer in Natural Waters. Academic Press, San Diego, California.

Montgomery Watson. 1995. Allowable Gas Supersaturation for Fish Passing Hydroelectric Dams. Bellevue, Washington. Prepared for the Bonneville Power Administration, Portland, Oregon.

Moursund RA, TJ Carlson, and RD Peters. 2003a. "A Fisheries Application of a Dual-Frequency Identification Sonar Acoustic Camera.” ICES Journal of Marine Science 60(3):678-683.

Moursund RA, DD Dauble, and MJ Langesley. 2003b. "Turbine Intake Diversion Screens: Investigating Effects on Pacific Lamprey." HydroReview 22(1):40-46.

Moursund RA, KD Ham, PS Titzler, and F Khan. 2004. Hydroacoustic evaluation of spill treatments on fish passage at Ice Harbor Dam in 2003. PNWD-3420. Prepared by Pacific Northwest National Laboratory for the U.S. Army Corps of Engineers, Walla Walla District, Walla Walla, Washington.

Neitzel DA, MC Richmond, DD Dauble, RP Mueller, RA Moursund, CS Abernethy, GR Guensch, and GF Čada. 2000. Laboratory Studies of the Effects of Shear on Fish. DOE/ID-10822, prepared by Pacific Northwest National Laboratory, Richland, Washington, for the Advanced Hydropower Turbine Systems Team, U.S. Department of Energy, Idaho Falls, Idaho.

Odeh M, JF Noreika, A Haro, A Maynard, T Castro-Santos, and GF Čada. 2002. Evaluation of the Effects of Turbulence on the Behavior of Migratory Fish. DOE/BP-00000022-1, prepared by the U.S. Geological Survey and Oak Ridge National Laboratory for the Bonneville Power Administration, Portland, Oregon.

Seyrafi K and SA Hovanessian. 1993. Introduction to Electro-Optical Imaging and Tracking Systems. Artech House, Norwood, Massachusetts.

Sidney FR (ed.). 2002. High Speed Photography and Photonics. International Society for Optical Engineering, Bellingham, Washington.

Urick RJ. 1983. Principles ofUnderwater Sound, $3^{\text {rd }}$ edition. Peninsula Publishing, Los Alos, California.

US Army Corps of Engineers Portland District, Walla Walla District, Hydroelectric Design Center, and Engineer Research and Development Center, 2004. Turbine Survival Program: Phase 1 report 19972003. Portland, Oregon. 
Wittinger RJ, J Ferguson, and TJ Carlson. 1995. Proceedings of the Turbine Passage Survival Workshop, Portland, Oregon. Prepared by the U.S. Army Corps of Engineers and Pacific Northwest National Laboratory, Portland, Oregon. 
